\title{
Influence of hydrothermal alteration on the elastic behaviour and failure of heat-treated andesite from Guadeloupe
}

\author{
A. Nicolas, ${ }^{1,2}$ L. Lévy, ${ }^{1,3}$ O. Sissmann, ${ }^{4}$ Z. Li, ${ }^{1}$ J. Fortin, ${ }^{1}$ B. Gibert ${ }^{5}$ and F. Sigmundsson ${ }^{3}$ \\ ${ }^{1}$ Laboratoire de Géologie, Ecole Normale Supérieure - PSL Research University, CNRS, UMR 8538, Paris, France.E-mail: aurelien.nicolas89@gmail.com \\ ${ }^{2}$ Now at: Cellule Recherche et Developpement, Eurofins Analyses pour le Bâtiment France, 20 rue du Kochersberg, 67700, Saverne, France \\ ${ }^{3}$ Nordic Volcanological Center, Institute of Earth Sciences, University of Iceland, 101 Reykjavk, Iceland \\ ${ }^{4}$ IFP Energies Nouvelles, 92500 Rueil-Malmaison, France \\ ${ }^{5}$ CNRS, Géosciences Montpellier, UM2 5243-CC60, Université de Montpellier, Montpellier, France
}

Accepted 2020 September 5. Received 2020 September 4; in original form 2019 March 14

\begin{abstract}
SUMMAR Y
Studies on the mechanical behaviour of rocks, including volcanic rocks, usually seek for unaltered and simple material: rocks without macroscopic defects. However, volcanic rocks are often naturally altered due to the circulation of hydrothermal fluids. This alteration may influence mechanical and physical properties. Here, we study the effect of hydrothermal alteration on the elasticity and failure properties of andesite. A homogeneous block of natural andesite was retrieved from a quarry. Three samples were first heat-treated and then artificially altered at different temperatures by soaking them in a brine for one month at a pressure of $20 \mathrm{MPa}$ and temperatures of 80,180 and $280{ }^{\circ} \mathrm{C}$. Heat-treated unaltered and altered samples were hydrostatically loaded up to $50 \mathrm{MPa}$ and unloaded, while strains and elastic wave velocities were recorded. Samples were also triaxially deformed to failure at a constant strain rate and a confining pressure of $15 \mathrm{MPa}$. At ambient pressure, increased alteration temperature resulted in increased wave propagation velocity, thus increased dynamic elastic moduli. During hydrostatic loading, volumetric deformation at a given effective pressure decreased with alteration temperature denoting increased static elastic moduli. During triaxial loading, the degree of alteration decreased elastic compaction and peak stress at failure. These observations are interpreted as the result of microcracks in-filling by alteration minerals, and in particular smectite, a swelling-clay mineral with a low friction coefficient. The mechanical behaviour of a volcanic rock subjected to triaxial loading was modelled with a damage model based on crack propagation from pre-existing flaws. A decreasing friction coefficient within the flanks of the cracks leads to a decrease of the peak stress and explains the experimental observations.
\end{abstract}

Key words: Creep and deformation; Elasticity and anelasticity; Geomechanics.

\section{INTRODUCTION}

Understanding the mechanical behaviour of rocks in volcanic geothermal systems is important to predict induced seismicity and wellbore failure in industrial contexts such as geothermal reservoir engineering and $\mathrm{CO}_{2}$ sequestration. It is also important in the context of natural hazards related to fault-activation and to explain ground deformation in volcanic areas revealed by GPS and InSAR observations (e.g. Massonnet \& Sigmundsson 2000; Pedersen \& Sigmundsson 2004; Pagli et al. 2006). Numerous laboratory studies have exposed stress-strain relationships for a variety of unaltered volcanic rocks (e.g. Stanchits et al. 2006; Heap et al. 2009, 2011, 2015a; Adelinet et al. 2010; Fortin et al. 2011; Adelinet et al. 2013; Nara et al. 2013; Akamatsu et al. 2019). However, alteration minerals, and in particular swelling minerals, such as smectite, are abundant in volcanic geothermal systems (e.g. Reyes 1990; Meunier 2005; Beauchamps et al. 2019; Lévy et al. 2019c), in subduction zones (e.g. Hyndman et al. 1997; Passelègue et al. 2014) and at some major faults (e.g. Yamaguchi et al. 2011; Chester et al. 2013; Lévy et al. 2019b), where hot fluid circulation in the host rock (e.g. Geoffroy \& Dorbath 2008; Adelinet et al. 2011) causes dissolution and secondary mineralization (e.g. Browne 1978; Zimbelman et al. 2005; Navelot et al. 2018; Lévy et al. 2019a).

The presence of alteration minerals can significantly modify the mechanical behaviour of rocks, due to microstructural changes, as compared to unaltered rock (e.g. Heap et al. 2014, 2015b; Siratovich et al. 2014; Navelot et al. 2018; Mordensky et al. 2019). Indeed, small changes in microstructural parameters, such as porosity (e.g. 
Vajdova et al. 2004), pore size (e.g. Zhu et al. 2010), crack density and mean length (e.g. Keshavarz et al. 2010), mineralogical composition (e.g. Heap et al. 2014) and grain boundary structure and contact (e.g. Heap et al. 2014) are known to significantly modify the physical properties and thus affect the mechanical behaviour of volcanic rocks (Pola et al. 2012; Frolova et al. 2014; Meller \& Kohl 2014; Wyering et al. 2014; Navelot et al. 2018). A recent study showed that advanced argillic alteration of andesite can promote, under the same pressure conditions, a change in failure mode from brittle to ductile (Mordensky et al. 2019). Yet, the specific influence of alteration on the mechanical behaviour of geothermal volcanic reservoirs is still poorly understood (Siratovich et al. 2016).

Studying the specific influence of alteration on the elastic behaviour and failure properties of volcanic rocks requires the use of samples with identical initial microstructures but altered at different levels, which is difficult to find in nature (e.g. Heap et al. 2017) although some studies used a single block that preserved different degrees of alteration (e.g. Mordensky et al. 2019). To overcome this obstacle, a single block of homogeneous andesite was used as starting material and samples from this block were artificially altered. In total, six samples were drilled and prepared. Four of these six samples were heat-treated. Of these four heat-treated samples, one remained unaltered and three were altered at different levels, after heat-treatment. We report results of hydrostatic and triaxial loading experiments performed on untreated, unaltered heat-treated and artificially altered samples, all coming originally from the same lithology. During these experiments, evolution of $P$ - and $S$-wave velocities were measured to track the evolution of open porosity. Acoustic emissions were also recorded and localized. The evolution of the mineralogy with both the heat-treatment and the artificial alteration was also tracked, with a special focus on smectite and other clay minerals.

\section{MATERIAL AND METHODS}

\subsection{Starting material, heat-treatment and artificial alteration}

The ideal material would be different blocks of the exact same andesite, naturally altered at different levels. As it is difficult to find that in the field, a single block of homogeneous andesite was used and samples were artificially altered to different levels. The block was recovered from an outcrop below Mamelle pass at Guadeloupe, French West Indies. The area of Mamelle is known to be part of the calc-alkaline Northern Chain (e.g. Navelot et al. 2018), dating from $1.81 \pm 0.03$ to $1.15 \pm 0.02 \mathrm{Myr}$ ago [K-Ar ages, Samper et al. (2007)], and consists of voluminous lava flows and andesite and dacite domes (Komorowski et al. 2005). Chemical composition was measured by X-ray fluorescence (XRF) on powders and show that our sample is andesite (Table 1 and Fig. 1). The original andesite is formed of a groundmass with microlites and phenocrysts from tenths to hundreds of microns (Figs $2 \mathrm{a}$ and $\mathrm{b}$ ).

In total, six samples were drilled and prepared in various ways as detailed hereafter. All samples were cored in the same block, and thin sections were made in several parts of the block in different orientations to control the similarity of microstructures. Although no bedding was identified based on visual inspection and SEM analysis, all samples were cored parallel to each other, in order to avoid effects of preferential direction. After coring, faces were ground to ensure a good parallelism (precision of $10 \mu \mathrm{m}$ ). The
Table 1. Chemical composition determined by XRF analysis performed on powder of the block used in this study.

\begin{tabular}{lr}
\hline & $\begin{array}{c}\text { wt. per } \\
\text { cent }\end{array}$ \\
\hline $\mathrm{SiO}_{2}$ & 59.3 \\
$\mathrm{TiO}_{2}$ & 0.6 \\
$\mathrm{Al}_{2} \mathrm{O}_{3}$ & 15.5 \\
$\mathrm{Fe}_{2} \mathrm{O}_{3}$ & 5.8 \\
$\mathrm{MnO}$ & 0.1 \\
$\mathrm{MgO}$ & 2.3 \\
$\mathrm{CaO}$ & 6.4 \\
$\mathrm{Na} \mathrm{O}_{2} \mathrm{O}$ & 3.5 \\
$\mathrm{~K}_{2} \mathrm{O}$ & 1.2 \\
$\mathrm{P}_{2} \mathrm{O}_{5}$ & 0.1 \\
$\mathrm{CO}_{2}$ & 5.2 \\
$\mathrm{Total}$ & 100 \\
\hline
\end{tabular}

resulting cylindrical samples have a diameter of $40 \mathrm{~mm}$ and a length of $80 \pm 2 \mathrm{~mm}$.

Due to the low permeability of the samples $\left(\approx 10^{-21} \mathrm{~m}^{2}\right)$, intense micro-fracturing was induced by heat-treatment to ensure to be able to saturate the samples with fluids (e.g. Katayama et al. 2018) and enable artificial alteration that is homogeneously distributed throughout the sample volume. Following previous studies focusing on the influence of heat-treatment on the mechanical behaviour and permeability of andesite (Kluge et al. 2017; Li et al. 2019; Nicolas et al. 2020), four samples (amongst the six initially drilled) were heat-treated at $930^{\circ} \mathrm{C}$ with a programmable Meker MHT-3 furnace, following the procedure described in Nicolas et al. (2014). Intact samples were heated at a rate of $120^{\circ} \mathrm{C} \mathrm{hr}^{-1}$, up to $930{ }^{\circ} \mathrm{C}$, kept $2 \mathrm{hr}$ at the maximum temperature, and then cooled at $120^{\circ} \mathrm{C} \mathrm{hr}^{-1}$, to avoid any quenching or thermal shocking effect. Heat-treated sample (AL-NA-TT) has a higher fracture density than the intact sample (AL-NA-NTT1), as shown in Fig. 2. All the samples show higher fracture density after heat treatment at $930{ }^{\circ} \mathrm{C}$ compared to the intact sample, as supported by a decrease in $P$-waves velocities measured axially from 4.9 to $2.8 \mathrm{~km} \mathrm{~s}^{-1}$ (Fig. 3b). This intense microfracturing, increasing the crack surface area and permeability (e.g. Darot et al. 1992), is due to the different thermal expansion coefficients of minerals (e.g. Fredrich \& Wong 1986) and the $\alpha-\beta$ transformation of quartz above $550{ }^{\circ} \mathrm{C}$ (e.g. Glover et al. 1995).

Three (amongst the four) heat-treated samples were altered during 1 month in an autoclave, saturated with a fluid at a pressure of 200 bar and at temperatures of 80,180 and $280^{\circ} \mathrm{C}$, respectively. A description of the samples used in this study, along with their identification numbers, can be found in Table 2. The fluid was prepared to be as close as possible to the seawater at Rocroy beach, next to the outcrop where the rock was recovered. The composition of the seawater at Rocroy beach was reproduced by mixing aqueous silica $\left[\mathrm{SiO}_{2}(\mathrm{aq})\right]$ and dissolving salts in the form of $\mathrm{M}(x+) \mathrm{Cl}(-) x$, with $\mathrm{M}$ being the cation and $x$ its valency ( 1 or 2$)$, in ultrapure deionized water (18.2 M $\Omega$ ). This composition is reported in Table 3. First, the heat-treated core samples were saturated under vacuum with fluid, and then placed in the autoclave pre-filled with the same fluid. The surrounding fluid was stirred for the duration of the experiment, and its composition allowed to evolve as the fluid reached thermodynamic equilibrium with new minerals (see Section 3.1.2). The alteration process produced in the three experiments is that of a closed system. It can be considered as an analog reproduction of certain natural alteration processes, in which the fluid stays stagnant or circulates with a slow flow rate, thus reaching a themodynamic equilibrium with certain minerals, and precipitating new secondary 


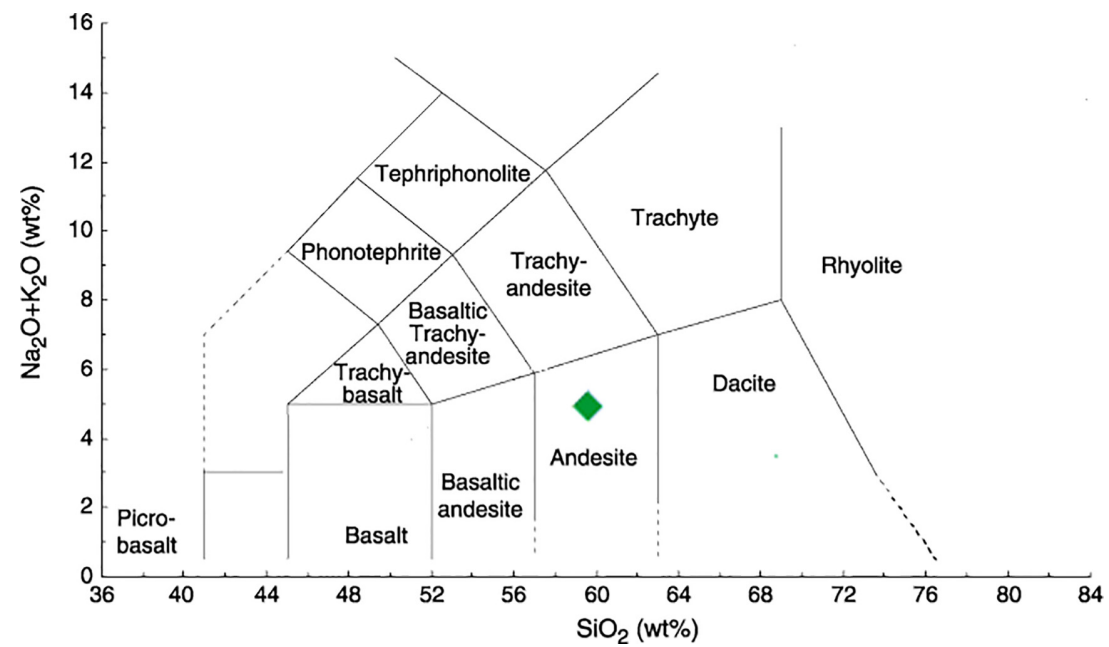

Figure 1. Total alkali-silica diagram for volcanic rocks classification, showing the weight percent of the total alkali elements $\left(\mathrm{Na}_{2} \mathrm{O}+\mathrm{K}_{2} \mathrm{O}\right)$ versus $\mathrm{SiO}_{2}(\mathrm{e} . \mathrm{g}$. Le Bas et al. 1986). Our block is represented by the green diamond and corresponds to the andesite group.
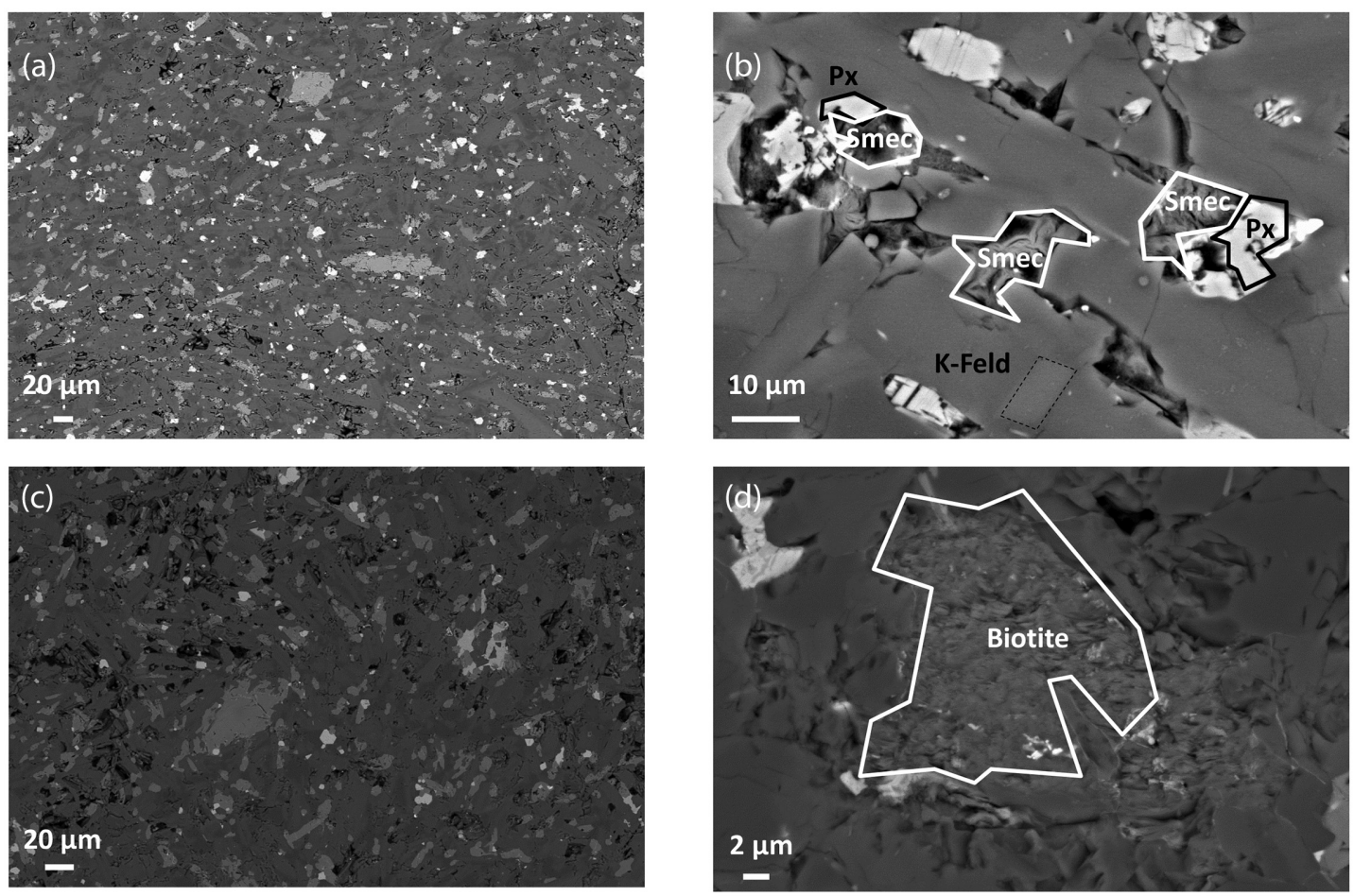

Figure 2. SEM observations of the mineralogy before (panels (a) and (b), sample AL-NA-NTT1) and after heat-treatment (panels (c) and (d), sample AL-NATT). Panels (b) and (d) show a zoom of a particular area of panels (a) and (c), respectively. K-feldspars 'K-Feld', smectites 'Smec' and pyroxenes 'Px' can be observed. Smectite 'Smec', of magnesium-rich character (saponite type) was evidenced by chemical analyses (Enegery Dispersive Spectroscopy) in the near vicinity of pyroxenes 'Px'. These occurrences of smectite, as replacement of pyroxenes, indicate that the original sample was not completely unaltered but had already started to be naturally altered. After heat-treatment, no smectite is observed but evidences of biotite are found by chemical analyses (panel d).

phases. The three alteration temperatures were chosen to represent continuum up to the maximum alteration temperature of around 300 ${ }^{\circ} \mathrm{C}$ recorded at Bouillante geothermal field in Guadeloupe (Jaud \& Lamethe 1985; Traineau et al. 1997).

\subsection{Characterization of mineral composition}

Large volumes of rock powder were prepared from each dried whole rock samples (crushed in an agate mill) and mixed, in order to reduce even minor variations on the microscale within each sample.
The primary minerals and artificial alteration products were characterized by quantitative analyses of X-ray diffraction (XRD) patterns measured on the fraction $<2 \mu \mathrm{m}$ of powders, cation exchange capacity (CEC) measurements on powders of rock samples and scanning electron microscope (SEM) observations on thin sections associated to chemical analyses by energy dispersion spectroscopy (EDS).

The CEC was measured by back-titration of the molecule Coppertriethylenetetramine (II), which replaces all exchange cations in minerals subject to cation exchanges. A protocol using this 

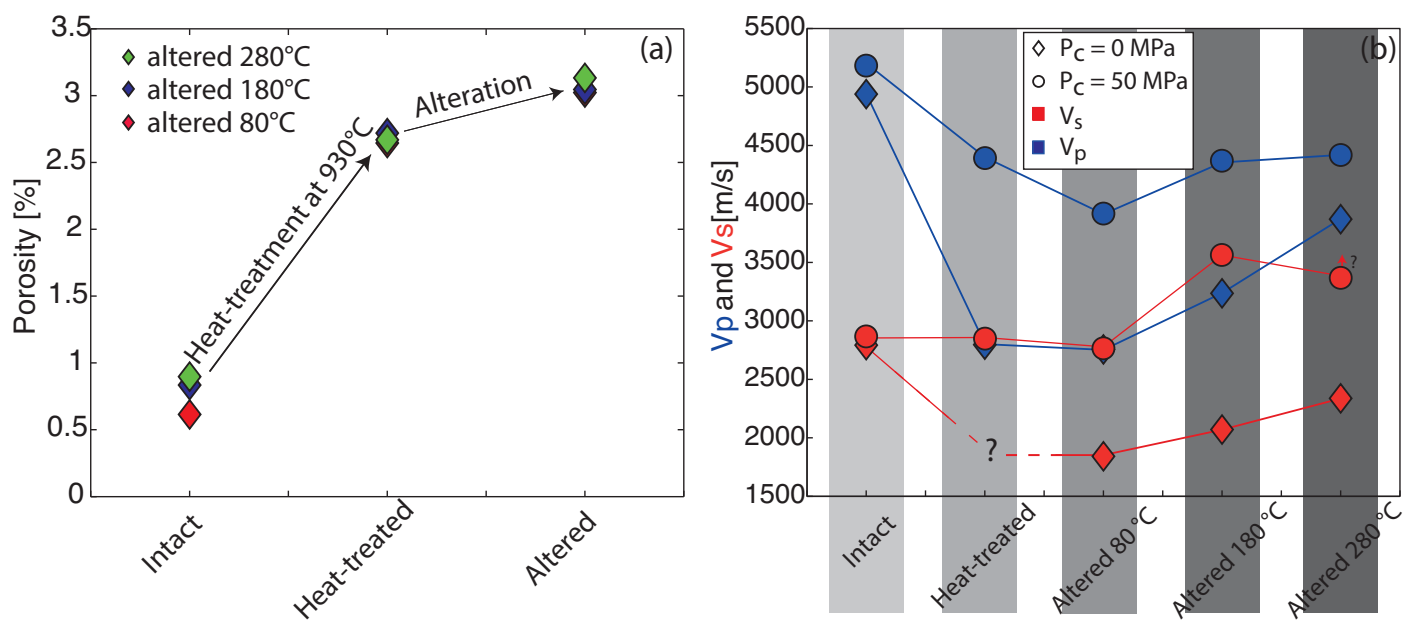

Figure 3. (a) Evolution of connected porosity during the alteration process of samples altered at $80{ }^{\circ} \mathrm{C}$ (red diamonds), $180{ }^{\circ} \mathrm{C}$ (blue diamonds) and $280{ }^{\circ} \mathrm{C}$ (green diamonds). (b) Axial $V_{P}$ at ambient pressure (blue diamonds), axial $V_{S}$ at ambient pressure (red diamonds), radial $V_{P}$ under a confining pressure of 50 MPa (blue circles), and radial $V_{S}$ under a confining pressure of $50 \mathrm{MPa}$ (red circles) of an intact sample (sample AL-NA-NTT1), a heat-treated sample (sample AL-NA-TT) and samples altered at $80^{\circ} \mathrm{C}$ (sample AL-80), $180{ }^{\circ} \mathrm{C}$ (sample AL-180) and $280{ }^{\circ} \mathrm{C}$ (sample AL-280). Due to attenuation, the first arrival time could not be peaked for the heat-treated sample (sample AL-NA-TT), leading to an over uncertainty shown by the question mark for this sample.

Table 2. Description of the six samples used in this study, together with results from the CEC measurements. CEC measurements on untreated samples were carried out on rock powders coming from the initial block, independently of the other experiments. CEC measurements on heat-treated unaltered samples were carried out on a rock powder from the core sample that had been heat-treated but not altered. CEC measurements on altered samples were carried out on rock powder taken from the core sample after all experiments were completed.

\begin{tabular}{llc}
\hline ID & Description & $\begin{array}{c}\text { CEC } \\
\text { meq/100g }\end{array}$ \\
\hline AL-NA-NTT1 & Untreated sample, taken inside the block & $3.26 \pm 0.20$ \\
AL-NA-NTT2 & Untreated sample, taken outside the block & $1.08 \pm 0.14$ \\
AL-NA-TT & Heat-treated but unaltered, reference sample & $0.00 \pm 0.00$ \\
AL-80 & Heat-treated and altered at $80^{\circ} \mathrm{C}$ & $0.00 \pm 0.20$ \\
AL-180 & Heat-treated and altered at $180^{\circ} \mathrm{C}$ & $0.00 \pm 0.20$ \\
AL-280 & Heat-treated and altered at $280^{\circ} \mathrm{C}$ & $0.48 \pm 0.13$ \\
\hline
\end{tabular}

molecule, originally developed to measure the CEC on pure clay minerals (Meier \& Kahr 1999) and adapted to measure the CEC as well as quantify the smectite content of altered volcanic rocks was used here (Lévy et al. 2018, 2020). The results of the CEC measurements for all samples can be found in Table 2, together with estimated uncertainties.

The XRD patterns were analysed with the Rietveld refinement method using the BGMN software (Taut et al. 1998) to provide a quantification of the mineralogy (Table 4).

Fluids were analysed by atomic emission spectroscopy in an inductively coupled plasma (ICP-AES). Each fluid sample was analysed three times, and an average was calculated to produce the composition value. Uncertainty is based on the standard deviation obtained on an external standard. The fluid compositions before contact with the rock, after equilibration with the unaltered samples and after alteration at 80,180 and $280{ }^{\circ} \mathrm{C}$ are reported in Table 3.

\subsection{Petrophysical properties}

Connected porosities of the untreated cores were measured using a triple weight procedure during which samples were saturated with water (saturation being performed under vacuum) during $12 \mathrm{hr}$ after being oven-dried for several days. Note that the way connected porosities were measured may be affected by swelling properties of smectite potentially overestimating the connected porosity by water uptake in the silicate structure. $P$ and $S$-wave velocities were measured on dried cores using piezoelectric transducers (PZTs; $1 \mathrm{MHz}$ resonance frequency) as detailed in the next section. These measurements were repeated after heat-treatment and after alteration.

\subsection{Experimental apparatus}

In this paper, compressive stresses and compactive strains are counted positive. The principal stresses will be denoted $\sigma_{1}$ and $\sigma_{3}, \sigma_{1}$ being the highest principal stress and $\sigma_{3}$ the confining pressure. The differential stress $\sigma_{1}-\sigma_{3}$ will be denoted $Q$ and the mean stress $\left(\sigma_{1}+2 \sigma_{3}\right) / 3$ will be denoted $P$.

The pressure vessel used in this study is a conventional triaxial cell installed in the Laboratoire de Géologie at the École Normale Supérieure in Paris. Axial stress was applied on the base areas of the cylindrical core sample by an axial piston. This externally applied axial stress was measured with an uncertainty of about $10^{-2} \mathrm{MPa}$. 


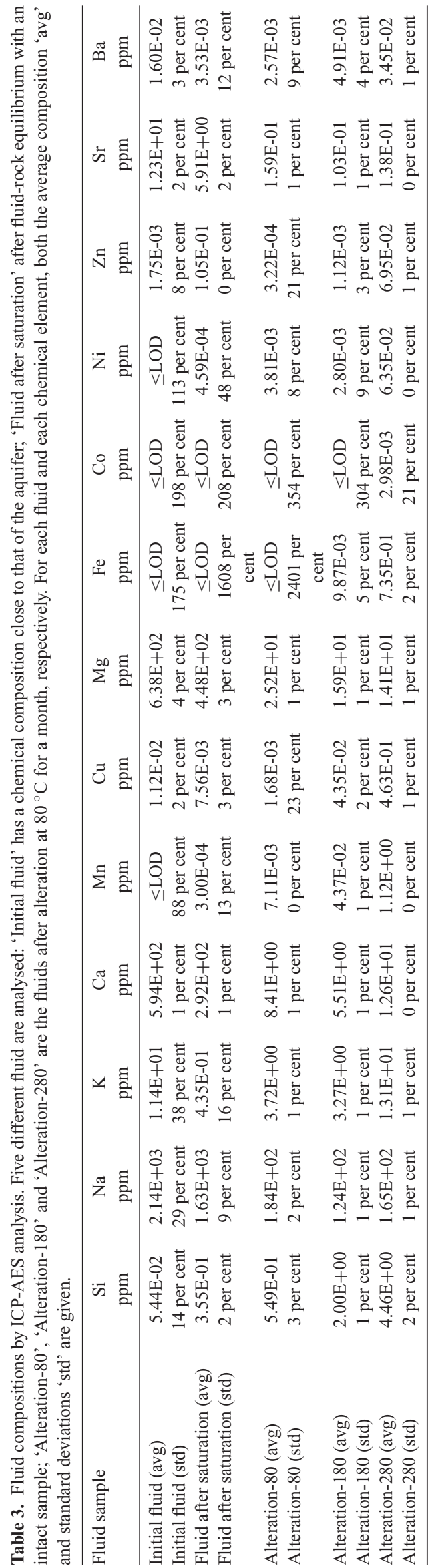

Radial sample deformation leads to another source of uncertainty $:$ at the peak stress, the radial strain (perimeter increase) reaches a maximum value of 0.5 per cent and thus the transverse section area changes by up to 1 per cent during the deformation. This causes an uncertainty of about 1 per cent on the calculated axial stress within the core sample. Since the measurement uncertainty $\left(10^{-2} \mathrm{MPa}\right)$ is negligible compared to the applied stress, in the range 10-100 $\mathrm{MPa}$, the total uncertainty on the axial stress applied to the sample is 1 percent. Radial pressure was controlled by a pump and kept constant within $10^{-1} \mathrm{MPa}$. The confining pressure $\left(\sigma_{2}=\sigma_{3}\right)$ was measured by a pressure transducer with an accuracy of about $10^{-2} \mathrm{MPa}$. A detailed description of the apparatus can be found in Brantut et al. (2011) and Ougier-Simonin et al. (2011). Strains were measured using double strain gauges (Tokyo Sokki TML type FCB 2-11), directly centrally glued on the sample. These gauges were composed of one axial and one radial gauge. The axial displacement was measured with three DC displacement transducers (DCDT), mounted outside the pressure vessel between the moving piston and the fixed lower platen. For both strain gauges and DCDTs, mean displacements were considered. The DCDT measurements were corrected for the stiffness of the cell, using the strain gauge measurements. The strain uncertainty measured with gauges was estimated to $10^{-5}$. DCDT signals lead to a strain accuracy of about $10^{-4}$. The volumetric strain was calculated as $\varepsilon_{v}$ $=\varepsilon_{a x}+2 \varepsilon_{r}$, where $\varepsilon_{a x}$ and $\varepsilon_{r}$ are the axial and radial strains, respectively.

Before gluing the acoustic sensors and performing the mechanical experiments, samples were dried in an oven at $\sim 40{ }^{\circ} \mathrm{C}$ for several days. Neoprene tubing was used to separate the sample from oil confining medium. In addition to the gauges, 16 piezoelectric transducers (PZTs; $1 \mathrm{MHz}$ resonance frequency) were glued directly onto the sample surface through holes drilled in the jacket. Among the sensors, 12 are sensitive to $P$ waves and the others to $S$ waves. Transducers were used as sources and receivers (active mode) to measure the evolution of $P$ - and $S$-wave velocities every 1 minutes during deformation (e.g. Fortin et al. 2007; Wang et al. 2012). Velocities were deduced from the ratio of the travelling time to the distance between two sensors. Arrival times were determined with an accuracy of $0.1 \mu \mathrm{s}$ (see Brantut et al. (2011) for a thorough description and a discussion regarding the acoustic system). This gives a maximum error of 5 percent for the elastic velocities. Time delay due to the sensor itself is taken into account and does not depend on confining pressure (validated by experiments done on aluminium). No other calibration is needed to determine the ultrasonic velocities. Acoustic sensors were also used in passive mode to record acoustic emissions occurring during rock deformation (e.g. Fortin et al. 2006, 2009). Acoustic emissions recorded during samples deformation and failure were relocalized using Insight Software. For relocalization, we use a constant velocity model with an anisotropy factor (ratio between axial and radial velocities) of 0.75 , in agreement with the ratio measured at failure around which most acoustic emission were recorded. A thorough description of the acoustic system can be found in Brantut et al. (2011).

To characterize the mechanical behaviour under (hydrostatic) pressure, confining pressure was increased from 0 to $50 \mathrm{MPa}$ at a rate of $3 \mathrm{MPa} \mathrm{min}^{-1}$. The maximum pressure was maintained constant for around $10 \mathrm{~min}$ and the sample was then unloaded from 50 to $0 \mathrm{MPa}$. After that, samples were reloaded hydrostatically up to the desired confining pressure of $15 \mathrm{MPa}$. The differential stress was then applied by deforming the sample at a controlled strain rate of $\sim 10^{-5} \mathrm{~s}^{-1}$, until failure. 
Table 4. Mineral content of all samples, according to Rietveld-refinement of XRD patterns measured on whole rock powders. In the Table, DL and QL stand for detection and quantification limits. Clay minerals that were detected by XRD on fine fraction or by electron microscopy analysis, but not clearly visible on the XRD scans of the whole rock powders (in particular biotite for sample AL-NA-NTT-1 and AL-NA-TT), are indicated by $\leq$ QL: they are below quantification limits because not clearly seen in whole rock samples, but they are nevertheless observed. Note that quantification by XRD for clay minerals (smectite, biotite) on whole rock samples is uncertain below 3 per cent.

\begin{tabular}{|c|c|c|c|c|c|c|c|c|c|c|c|}
\hline Sample & $\begin{array}{l}\text { Labradorite } \\
\text { (per cent) }\end{array}$ & $\begin{array}{l}\text { Albite (per } \\
\text { cent) }\end{array}$ & $\begin{array}{l}\text { Sanidine } \\
\text { (per cent) }\end{array}$ & $\begin{array}{l}\text { Augite (per } \\
\text { cent) }\end{array}$ & $\begin{array}{l}\text { Quartz (per } \\
\text { cent) }\end{array}$ & $\begin{array}{l}\text { Tridymite } \\
\text { (per cent) }\end{array}$ & $\begin{array}{l}\text { Crystobalite I } \\
\text { (per cent) }\end{array}$ & $\begin{array}{l}\text { I Ilmenite(pe } \\
\text { cent) }\end{array}$ & $\begin{array}{l}\text { erHematite( } p \\
\text { cent) }\end{array}$ & $\begin{array}{l}\text { pesmectite(peB } \\
\text { cent) }\end{array}$ & $\begin{array}{l}\text { Biotite(per } \\
\text { cent) }\end{array}$ \\
\hline AL-NA-NTT1 & 67 & 5 & 6 & 7 & 8 & 3 & $\leq \mathrm{DL}$ & $\leq \mathrm{DL}$ & 1 & 3 & $\leq \mathrm{QL}$ \\
\hline AL-NA-NTT2 & 26 & 43 & 9 & 9 & 7 & 3 & $\leq \mathrm{DL}$ & $\leq \mathrm{DL}$ & 2 & 1 & $\leq \mathrm{DL}$ \\
\hline AL- 80 & 31 & 38 & 5 & 11 & 7 & 2 & 3 & $\leq \mathrm{DL}$ & 2 & $\leq \mathrm{DL}$ & $\leq \mathrm{DL}$ \\
\hline AL-180 & 32 & 41 & 6 & 6 & 6 & 2 & 2 & 1 & 2 & $\leq \mathrm{DL}$ & $\leq \mathrm{DL}$ \\
\hline AL-280 & 31 & 44 & 6 & 7 & 7 & 2 & $\leq \mathrm{DL}$ & 1 & 2 & $\leq \mathrm{QL}$ & $\leq \mathrm{DL}$ \\
\hline
\end{tabular}

\section{RESULTS}

\subsection{Evolution of mineralogy with heat-treatment and alteration}

The content of major mineral phases for the fraction $<2 \mu \mathrm{m}$ is similar between untreated, heat-treated unaltered and heat-treated altered sample (see Table 4): 70-75 per cent of plagioclases (labradorite, albite), 5-10 per cent of K-feldspars (sanidine), 5-10 per cent of pyroxene (augite), 2-3 per cent of $\mathrm{SiO}_{2}$ (quartz, trydimite, crystobalite) and 2-3 per cent of iron-oxide (ilmenite, hematite). Rietveldrefinements of XRD analyses do not allow drawing a clear trend for the evolution of these minerals with heat-treatment and alteration. This section focuses on the variations of the clay mineral content (minor phases) after heat-treatment and alteration.

\subsubsection{Effects of heat-treatment}

Two different clay minerals were identified in the starting, untreated, material: smectite and potentially biotite. Based on the presence of a clear peak at $7 \AA$ in the XRD pattern of sample AL-NA-NTT1, measured on clay fraction, we consider that the presence of chlorite is likely (Fig. 4). The main desired effect of heat-treatment was to increase the connected porosity in order to increase the permeability and enable homogeneous fluid saturation for alteration. But a side effect is the dehydration and, most often, dehydroxylation of clay minerals after they undergo a temperature of $930{ }^{\circ} \mathrm{C}$.

Smectite is identified in the original block of andesite, as illustrated by the XRD patterns on fine fraction (Fig. 4) and chemical analyses of SEM images (Fig. 2) carried out on sample AL-NANTT1. Moreover smectite is consistently quantified on two samples from the original block of andesite, by XRD patterns on whole-rock (Table 4) and CEC measurements (Table 2), with 3 wt. per cent in sample AL-NA-NTT1 and 1 wt. per cent in sample AL-NA-NTT2. Indeed, the $\mathrm{CEC}$ of altered volcanic rocks, measured by $\mathrm{Cu}$-trien, can be converted into weight fraction of smectite content: Smec wt. per cent $=\frac{C E C}{C E C_{0}}$, with $C E C_{0}=80-100 \mathrm{meq} \mathrm{g}^{-1}$ being the CEC of pure smectite (Lévy et al. 2018). Since AL-NA-NTT1 is located inside the block, it has been less exposed to leaching than ALNA-NTT2, located outside the block. Initial smectite content of all core samples have not been measured, in order not to damage the core before the mechanical experiment. Since all samples that were heat-treated and altered were taken from the inner part of the block, the value of 3 wt. percent is considered to be the initial quantity of smectite in the samples before heat-treatment. It is observed in Fig. 2 that smectite is associated to pyroxene replacement in the rock mass. As a consequence, the presence of smectite in the untreated samples is interpreted as the product of slow, diagenetic transformation of the volcanic groundmass, possibly aided by the presence of trapped fluids (e.g. residual magmatic water).

After heat-treatment, the smectite content drops to zero, according to CEC measurements and to the collapse of the characteristic $14 \AA$ peak observed in XRD patterns of the fine fraction (Fig. 4). As all smectite has collapsed after heat-treatment, we consider that initial smectite content does not affect the alteration process. Irreversible dehydration and loss of swelling properties of smectite occur at temperatures between 350 and $550{ }^{\circ} \mathrm{C}$ (e.g. Greene-Kelly 1953; Russell \& Farmer 1964) while dehydroxylation of smectite occurs at temperatures between 500 and $800{ }^{\circ} \mathrm{C}$ (e.g. Grim \& Rowland 1944; Mackenzie 1957; Malek et al. 1997). The heat-treatment at $930{ }^{\circ} \mathrm{C}$ therefore caused both an irreversible dehydration and a dehydroxylation of smectite crystals initially present.

Biotite is inferred from a characteristic peak on the XRD diffraction pattern of the fine fraction (Fig. 4). This peak alone does not allow the discrimination between biotite and illite. However, the presence of illite should be associated to the transformation of Kfeldspar and therefore located in the vicinity of K-feldspar minerals, similarly to smectite slowly transforming pyroxenes. K-Feldspars are unaltered, which indicates that the presence of illite is unlikely (Fig. 2b). Since biotite is a common primary mineral in andesistic magmas, the presence of biotite rather than illite is inferred.

Chemical analyses suggest the persistence of biotite after heattreatment (AL-NA-TT, Fig. 2d). The characterstic $10 \AA$ peak observed in the untreated samples AL-NA-NTT1 and AL-NA-NTT2 vanished almost completely in the heat-treated sample AL-NA-TT. This indicates that the crystalline network of biotite had started to collapse by dehydroxylation when the heat-treatment stopped but that the vitrification of biotite was not complete. This interpretation is strengthened by the high-thermal stability of biotite, up to 1000 ${ }^{\circ} \mathrm{C}$ (Skjerlie \& Johnston 1992).

The presence of chlorite can explain the $7 \AA$ peak observed on the XRD patterns of fine fraction (Fig. 4). Other characteristic peaks of chlorite diffraction $(14,4.7$ and $3.5 \AA$ ) tend to confirm this interpretation, although the background diffraction of non-clay minerals biases the XRD pattern, with in particular plagioclases remaining in the fine fraction. Since chlorite is commonly found as replacement of biotite in andesistic minerals (Rimsaite 1975), its presence in the intact sample is possible. The collapse of all the characteristic peaks associated to chlorite after heat-treatment is consistent with the fact that dehydroxylation of chlorite occurs at temperatures lower than $930{ }^{\circ} \mathrm{C}$ (Zhan \& Guggenheim 1995). Therefore, even if chlorite is present in the intact sample, it has 


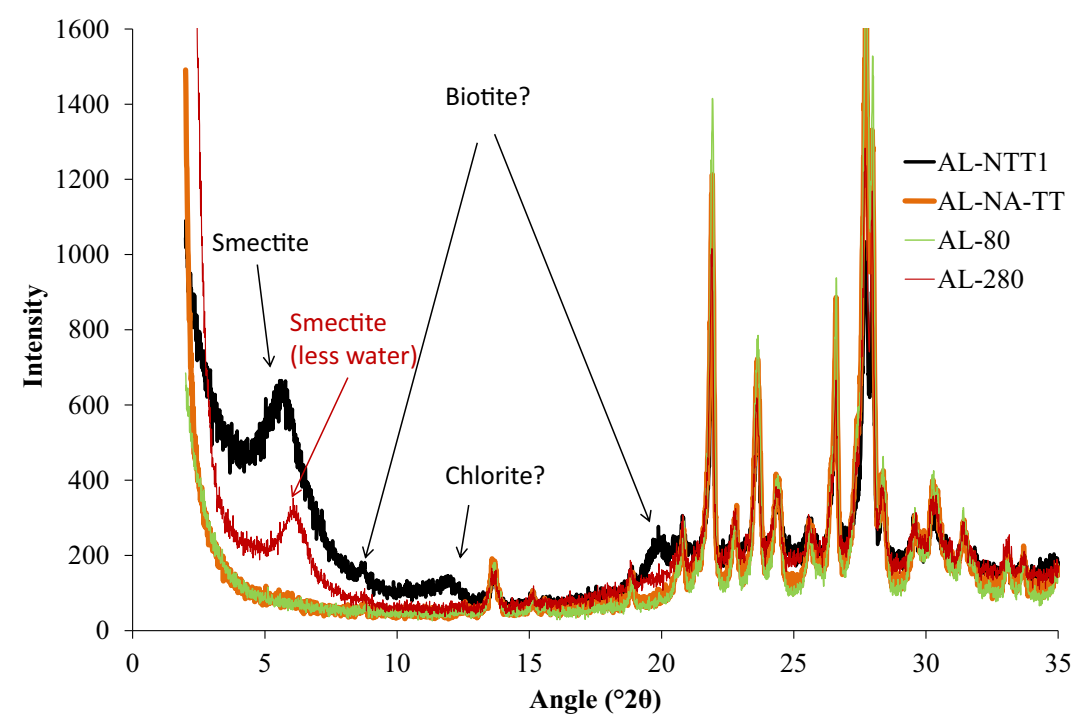

Figure 4. XRD patterns of all samples. The $x$-axis unit corresponds to twice the angle between the X-ray beam and the horizontal plane. It can be converted into distances between atomic layers in the crystal (in $\AA$ ), using Bragg's law: $d=\frac{\lambda}{2 \sin \theta}$, where $\lambda=1.54 \AA$ is the wavelength of the incident X-ray beam used in these measurements and $\theta$ is the incident beam angle, in rad. AL-NA-NTT1 corresponds to the intact andesite, AL-NA-TT to the heat-treated andesite, AL- 80 and AL-280 to andesite altered at 80 and $280^{\circ} \mathrm{C}$, respectively.

disappeared after heat-treatment. As a consequence, the only clay mineral possibly remaining after heat-treatment is ill-crystallized biotite, located in the rock groundmass (Fig. 2d).

\subsubsection{Effects of alteration}

After alteration in an autoclave during one month at $280{ }^{\circ} \mathrm{C}$, hints of alteration are observed. Precipitation of new smectite is evidenced by the characterstic $14 \AA$ peak in sample AL-280, which has undergone the highest level of alteration (Fig. 4). The presence of smectite in this sample is confirmed by CEC measurements: the same value of $0.48 \mathrm{meq}(100 \mathrm{~g})^{-1}$ is found after a duplicate analysis (two measurements per sample), using rock mass in the range 1-2 g. This value corresponds to about $0.5 \mathrm{wt}$. per cent smectite. Chemical analyses of SEM images confirm the presence of a phase having the chemical composition of a smectite, but this mineral is weakly crystallized (Fig. 5). Although smectite may rehydroxylate upon cooling in the presence of water (Drits et al. 1995), swelling properties (and thus cation exchange properties) are definitely lost (Greene-Kelly 1953). Moreover, the XRD peak is slightly shifted towards higher angles, compared to the smectite peak in the untreated samples (Fig. 4). Therefore, the increase in CEC and new $14 \AA$ peak upon artificial alteration at $280{ }^{\circ} \mathrm{C}$ is attributed to new precipitation of smectite in the connected fracture network. However, XRD quantification of the newly formed smectite on whole rock powders was not possible, due to its low amount below quantification limit.

While artificial alteration at $280^{\circ} \mathrm{C}$ of the heat-treated sample has led to an observable precipitation of smectite, effects of artificial alteration at 80 and $180^{\circ} \mathrm{C}$ are not clearly observed using SEM. In these samples altered at lower temperature, thermodynamic modelling performed with the CHESS reactive code and using the EQ3/6 database based on fluid analyses presented in Table 3, predicts that smectite is in thermodynamic equilibrium. The XRD patterns of AL-80 and AL-180 do not show hints of smectite presence and the CEC is below the detection limit. However, the presence of weakly crystallised smectite cannot completely be ruled out by these measurements.

\subsection{Evolution of petrophysical properties with heat-treatment and alteration}

The initial connected porosity is low $(0.8 \pm 0.3$ per cent, Fig. $2 a)$. Initial $P$ - and $S$-wave velocities are 4938 and $2792 \mathrm{~m} \mathrm{~s}^{-1}$, respectively (Fig. 3b).

\subsubsection{Effects of heat-treatment}

Heat treatment induces an increase in connected porosity from $0.8 \pm 0.3$ per cent to $2.6 \pm 0.1$ per cent (Fig. $3 a$ ), which can be explained by the propagation and opening of cracks due to differences in the coefficient of thermal expansion of the minerals and the dehydroxylation of clay minerals. $P$-waves velocities measured axially drop from 4.9 to $2.8 \mathrm{~km} \mathrm{~s}^{-1}$ (Fig. 3b), showing a crack density increase. The propagation and opening of new cracks can also be inferred from the microstructural observations (Fig. 2).

\subsubsection{Effects of alteration}

$P$ - and $S$-wave velocities under dry conditions and ambient pressure increase with alteration and the increase is more pronounced for higher alteration temperature: $P$-wave velocities increase from 2.8 to $3.2 \mathrm{~km} \mathrm{~s}^{-1}$ after alteration at $180{ }^{\circ} \mathrm{C}$ and to $3.9 \mathrm{~km} \mathrm{~s}^{-1}$ after alteration at $280{ }^{\circ} \mathrm{C}$ (Fig. 3b). Both $P$ - and $S$-wave velocities are systematically higher under a confining pressure of $50 \mathrm{MPa}$ than under ambient pressure (Fig. 3b), which can be explained by crack closure with pressure (Walsh 1965).

Artificial alteration leads to a slight increase in porosity $(+0.5$ per cent) (Fig. 3a), more pronounced with higher alteration temperature. Note that the increase in porosity could be biased by swelling clays, in particular when considering that the amount of smectite increases with alteration, and thus with higher alteration temperature. At this point, we cannot determine whether porosity increase is either due to new cracks and/or an increase in the volume of pre-existing cracks and/or an increase in the number or size of the equant pores within the rock. 

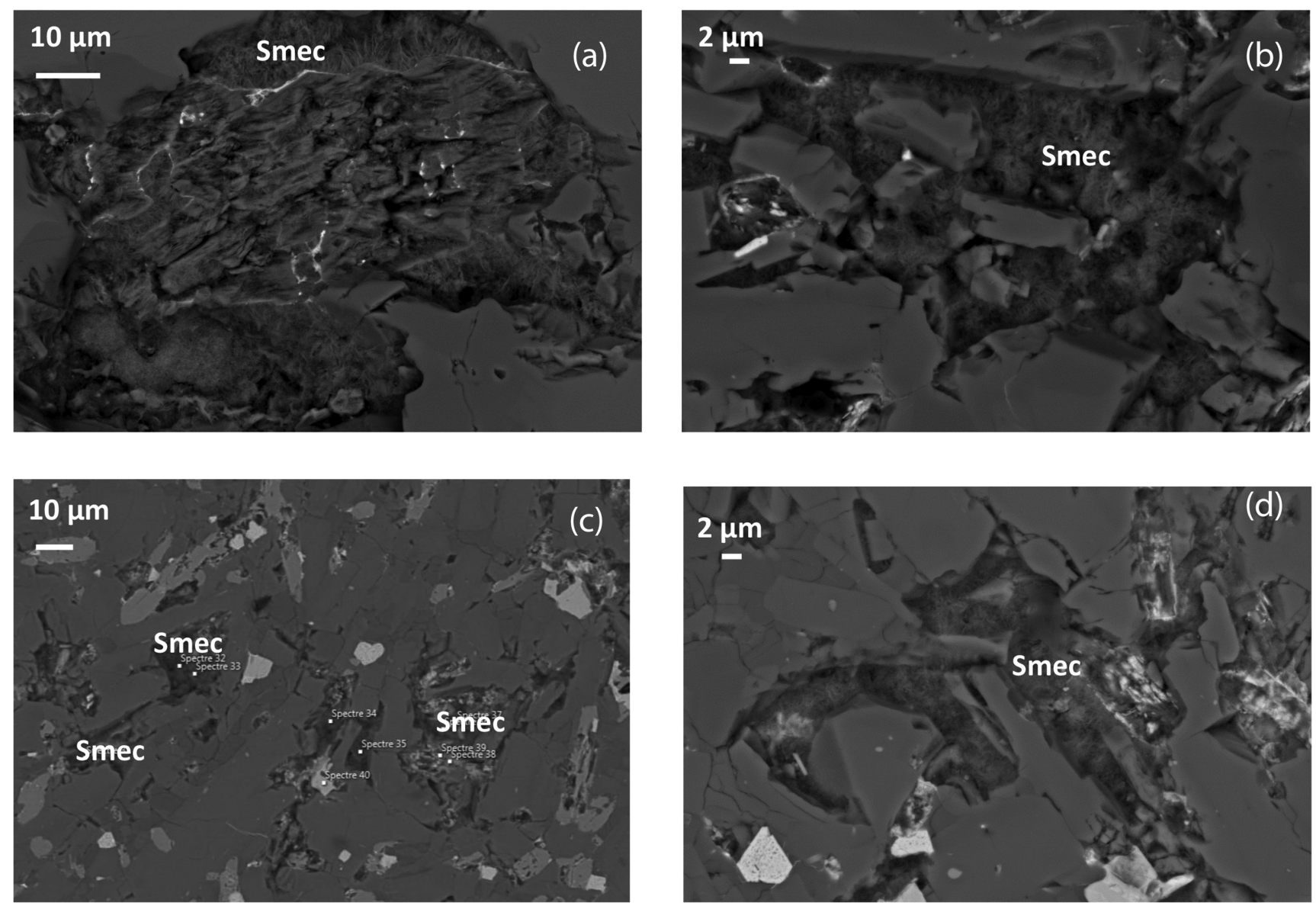

Figure 5. SEM observations of the sample altered at $280^{\circ} \mathrm{C}$ (AL-280). Newly formed smectite in the pores, evidenced by chemical analyses (energy dispersive spectroscopy), is indicated by 'Smec'.

\subsection{Evolution of the elastic behaviour under hydrostatic stress with heat-treatment and alteration}

Results for a hydrostatic loading experiment with up to $50 \mathrm{MPa}$ confining pressure performed on an intact sample, a heat-treated sample and samples altered at 80,180 and $280^{\circ} \mathrm{C}$ are presented in Fig. 6 (a). The stress-strain curve of the intact sample is linear with a slope corresponding to a static bulk modulus of $K=47 \pm 0.2$ $\mathrm{GPa}$. The mechanical behaviour of the heat-treated and the three altered samples is different. Stress-strain relations are non-linear for the investigated range of hydrostatic stresses, but static bulk moduli remain below the one determined for the intact sample even at the highest applied stresses, that is, above $\sim 38 \mathrm{MPa}$ hydrostatic stress the static bulk moduli were $K=15.9 \pm 0.2,15.9 \pm 0.2$, $16.2 \pm 0.2$ and $17.2 \pm 0.2 \mathrm{GPa}$ for the heat-treated sample and the samples altered at 80,180 and $280{ }^{\circ} \mathrm{C}$, respectively (Fig. 6a). The non-linearity observed can be explained by the progressive closure of pre-existing microcracks (e.g. Walsh 1965; Baud et al. 2000; Nicolas et al. 2016). The compaction has a hysteresis and after unloading, initial volume is not fully recovered but the samples exhibit some permanent strain. Comparing the volumetric strain measured and a theoretical perfectly elastic trend, microcrack porosity $\left(\phi_{c}\right)$ can be estimated (Walsh 1965). We find $\phi_{c} \sim 0.20,0.20,0.12$ and 0.10 per cent for the heat-treated sample and samples altered at 80 , 180 and $280^{\circ} \mathrm{C}$, respectively.

As pressure is increased from 0 to $50 \mathrm{MPa}, P$-wave velocity remains nearly constant for the intact sample. For the heat-treated sample, $P$-wave velocity increases by 55 percent as pressure is increased from 0 to $50 \mathrm{MPa}$. As pressure is increased from 0 to 50 $\mathrm{MPa}$ on altered samples, $P$-wave velocities increase by 55,35 and 20 per cent for samples altered at 80,180 and $280{ }^{\circ} \mathrm{C}$, respectively (Fig. 6b) and end up between 4000 and $4500 \mathrm{~m} \mathrm{~s}^{-1}$ with final values increasing with the temperature of alteration (Fig. 3b). Elastic wave velocities are directly related to the compaction of the samples (Fig. 6c). This increase highlights the closure of pre-existing cracks (e.g. Fortin et al. 2005). Under hydrostatic stress conditions, velocities derived from various paths did not show any evidence for anisotropic dynamic elastic properties and remained equal to a few tenths of percent (within uncertainty for these measurements, not shown in Fig. 3). These results indicate that the medium composed of groundmass with embedded pores and cracks is isotropic, in agreement with previous observations by Vinciguerra et al. (2005).

\subsection{Evolution of the mechanical behaviour during triaxial loading and failure with heat-treatment and alteration}

For all samples, the mechanical behaviour observed during constant strain rate triaxial deformation of the samples are typical of the brittle faulting regime: The response was non-linear up to a differential stress of $\approx 125 \mathrm{MPa}$, beyond which the axial strain versus differential stress curves first show a linear trend typical of an elastic behaviour (Fig. 7a). Then, the differential stress reaches a peak, beyond which strain softening is taking place, ultimately leading to 

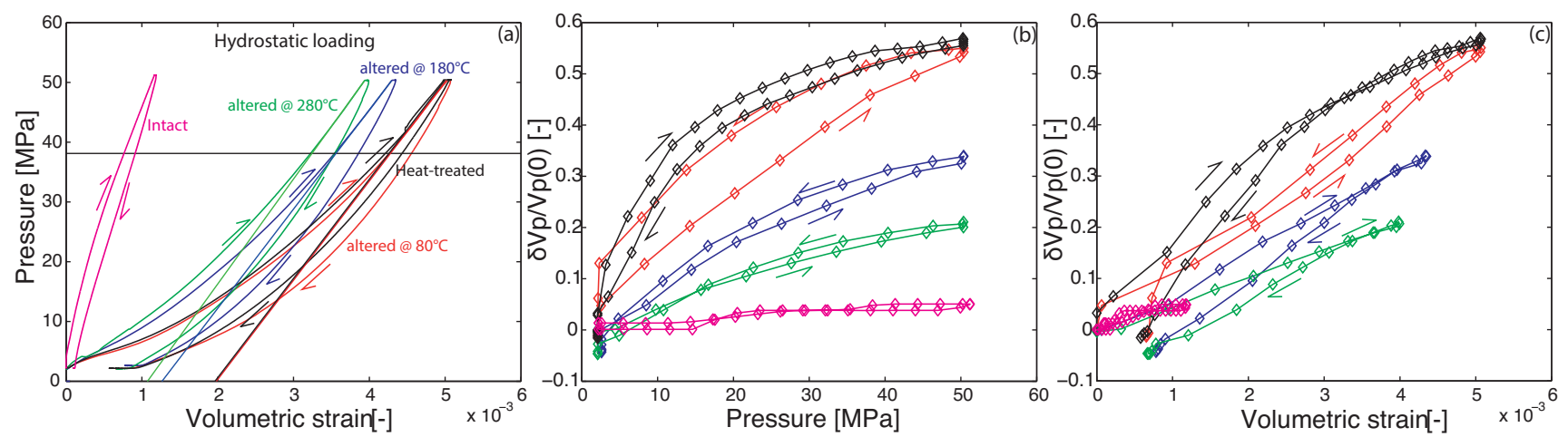

Figure 6. (a) Evolution of the confining pressure plotted versus volumetric strain for an intact sample (pink curve), a heat-treated sample (black curve) and samples altered at $80^{\circ} \mathrm{C}$ (red curve), $180^{\circ} \mathrm{C}$ (blue curve) and $280^{\circ} \mathrm{C}$ (green curve). Slope lines correspond to a perfectly elastic behaviour. (b) Evolution of unitless average radial $\delta V_{P} / V_{P 0}$ (where $V_{P 0}$ is the radial $P$-wave velocity at the beginning of isostatic loading) is plotted as a function of pressure for the previous samples. (c) Evolution of unitless average radial $\delta V_{P} / V_{P 0}$ (where $V_{P 0}$ is the radial $P$-wave velocity at the beginning of isostatic loading) is plotted as a function of volumetric strain for the previous samples.

macroscopic failure (Fig. 7a). From the axial strain versus differential stress curves (Fig. 7a), it can be seen that Young's modulus increases from $51 \pm 1$ to $60 \pm 1 \mathrm{GPa}$ with the alteration of the samples. From the volumetric strain versus mean stress curves (Fig. 7b), it can be seen that samples show an elastic compactant behaviour until a critical stress state denoted $C^{\prime}$ (Wong et al. 1997) beyond which the volumetric strain deviates from linear elasticity (onset of dilatancy). The critical stress state $C^{\prime}$ is determined manually at the point of divergence of the curve of volumetric strain versus mean stress and the linear elastic compaction of each experiment as discussed in Nicolas et al. (2016).

During triaxial loading of the non-altered sample, elastic compaction is followed by dilatancy, which leads to macroscopic failure. The two altered samples that were triaxially deformed show the same mean stress-volumetric strain relationship (Fig. 7b). Elastic compaction is highest for the non-altered sample.

Our results show that the peak stress (differential stress at failure) decreases with the degree of alteration (Fig. 8). The non-altered sample failed at a peak stress of $471 \mathrm{MPa}$, slightly higher than the sample altered at $180{ }^{\circ} \mathrm{C}$ which failed at a stress of $464 \mathrm{MPa}$. The sample altered at $280^{\circ} \mathrm{C}$ failed at a peak stress of $418 \mathrm{MPa}$, which is 11 per cent lower than the peak stress for the unaltered sample. Similarly to what is observed for the peak stress, the differential stress levels at the onset of dilatancy $\left(C^{\prime}\right)$ shows a negative alteration dependence (Fig. 8). Again, the stress at which dilatancy overcomes compaction $\left(D^{\prime}\right)$ decreases with the degree of alteration. For the intact sample, the onset of dilatancy $\left(C^{\prime}\right)$ and dilatancy $\left(D^{\prime}\right)$ are reached for stresses of 189 and $362 \mathrm{MPa}$, respectively. This is higher than the stresses for the sample altered at $180^{\circ} \mathrm{C}$, which reached the onset of dilatancy and dilatancy points at 165 and $286 \mathrm{MPa}$, respectively. Finally, the sample altered at $280{ }^{\circ} \mathrm{C}$ reached the onset of dilatancy and dilatancy at 165 and $285 \mathrm{MPa}$, respectively.

During the initial stage of elastic loading, $P$-wave velocities $\left(V_{p}\right)$ at all angles with respect to $\sigma_{1}$ and $S$-wave velocities $\left(V_{s}\right)$ increase with deformation for all samples (Fig. 9). The increase is maximum for the highest angles with respect to $\sigma_{1}$ and decreases with the angle. $P$-wave velocity increases reach 40,30 and 25 per cent for non-altered, altered at $180{ }^{\circ} \mathrm{C}$ and altered at $280{ }^{\circ} \mathrm{C}$ samples, respectively. Then, $V_{p}$ and $V_{s}$ start decreasing at the onset of dilatancy $\left(C^{\prime}\right)$ within axial strain of 0.1 per cent (Fig. 9). Beyond $C$ ', velocities continue to decrease as the sample is deformed until failure at which velocities drop abruptly. The overall decrease for both $V_{p}$ and $V_{s}$ reaches 60 per cent for the non-altered sample but tends to decrease with alteration. Under triaxial stresses, the maximum decrease is observed for the pathway perpendicular to $\sigma_{1}\left(90^{\circ}\right)$, which suggests that the propagating and/or nucleating cracks are mainly axial (Ayling et al. 1995; Mavko et al. 1995; Fortin et al. 2011; Nicolas et al. 2016, 2017b). Thus, we invert ultrasonic wave velocities in terms of axial and randomly oriented crack densities (Sayers \& Kachanov 1995) assuming: (1) a transverse isotropic crack geometry; (2) an isotropic groundmass, in agreement with the isotropic ultrasonic waves velocities measured under hydrostatic conditions; (3) non-interacting cracks, an assumption which is valid for crack densities up to at least 0.15 and probably $0.2-0.25$ (Grechka \& Kachanov 2006); (4) a random crack centre distribution and (5) penny-shape cracks of radius $c$ and aperture $w$. The detailed procedure can be found in Fortin et al. (2011) and in appendix A in Wang et al. (2013). When the differential stress is increased, the axial and background crack densities decrease during the elastic compaction of all experiments (Fig. 9). Beyond that stage, the axial crack density increases immediately beyond the onset of dilatancy $\left(C^{\prime}\right)$ and reaches values up to 2 at macroscopic failure (Fig. 9d). Inverted crack densities increase less for altered samples. Note that the assumption that neglects cracks interaction is no more valid for crack density above 0.2 ; which means that in this case the crack density might be slightly overestimated. Moreover, when localization of damage takes place, effective medium theory cannot be applied anymore, and thus crack density inferred after the peak stress needs to be taken with caution.

Post-mortem observations show a shear plane inclined with regards to the maximum principal stress for all samples, demonstrating that they all exhibit brittle behaviour.

\section{DISCUSSION}

\subsection{Alteration, porosity and density}

Alteration leads to a modest increase in connected porosity (Fig. 3a). Note that the way connected porosities were measured may be affected by swelling properties of smectite potentially overestimating the connected porosity by water uptake in the silicate structure. A positive correlation between porosity and quantity of alteration has also been noticed in natural samples from a hydrothermal system 

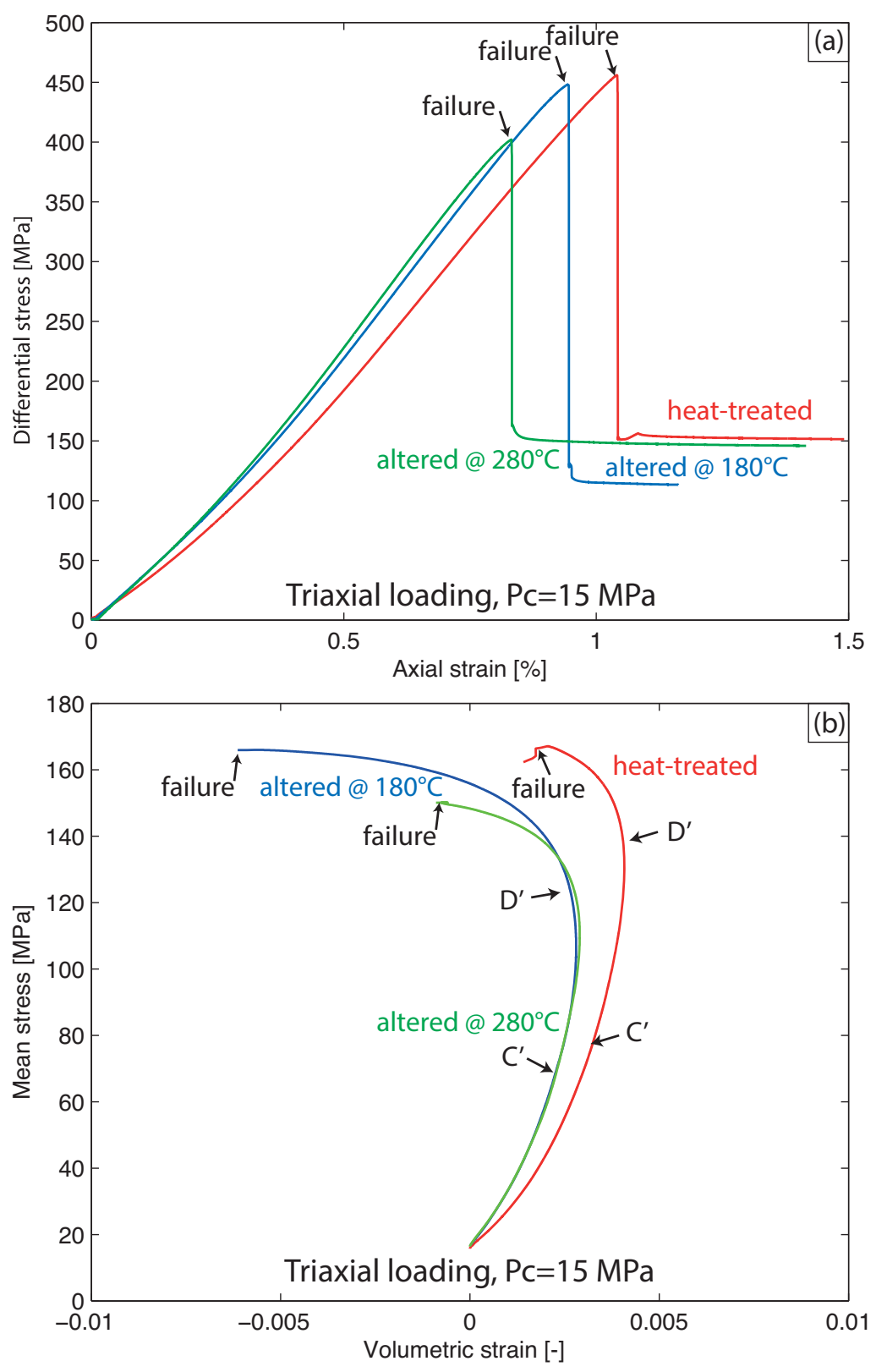

Figure 7. (a) The differential stress is plotted versus axial strain for constant strain rate deformation experiments performed on heat-treated sample, and samples altered at 180 and $280^{\circ} \mathrm{C}$ at a confining pressure of $15 \mathrm{MPa}$. The mean stress versus volumetric strain curves for these three experiments are shown in panel (b).

in Iceland (Lévy et al. 2018). Levy and coworkers explained this correlation by a lithological control on both porosity and alteration. Given that the original lithology and porosity of all samples is very similar in this study, this explanation does not apply. An actual control of the alteration on the porosity seems to appear, as also evidenced by Mordensky et al. (2018) who found that argillic alteration of andesite decreased porosity due to pore- and microcrack-filling alteration.

The presence of smectite in the sample altered at $280{ }^{\circ} \mathrm{C}$ is evidenced by SEM-EDS analyses, XRD on fine fraction and CEC measurements. Microcrack porosity decrease with the level of alteration (inferred from hydrostatic mechanical data, Fig. 6a) and consistent increase in elastic wave velocities under room pressure with the level of alteration (none, 80,180 and $280^{\circ} \mathrm{C}$ ) is also an indirect observation of smectite infilling in cracks because elastic wave velocities are much more sensitive to cracks than to equant pores (Fortin et al. 2007).

\subsection{Can smectite precipitation in cracks explain the mechanical behaviour?}

The increase of alteration level induces an increase in the elastic mechanical modules, which results in an increase in the velocity of propagation of the elastic waves and a lower volumetric deformation during isostatic loadings. The increase in the alteration also causes a decrease of the compaction under isostatic conditions and a decrease of the stress state at which the onset of dilatancy (C') occurs, the stress state at which dilatancy overcomes compaction (D') and finally the differential stress at failure occurring in a brittle manner during constant strain rate deformation experiments. The 


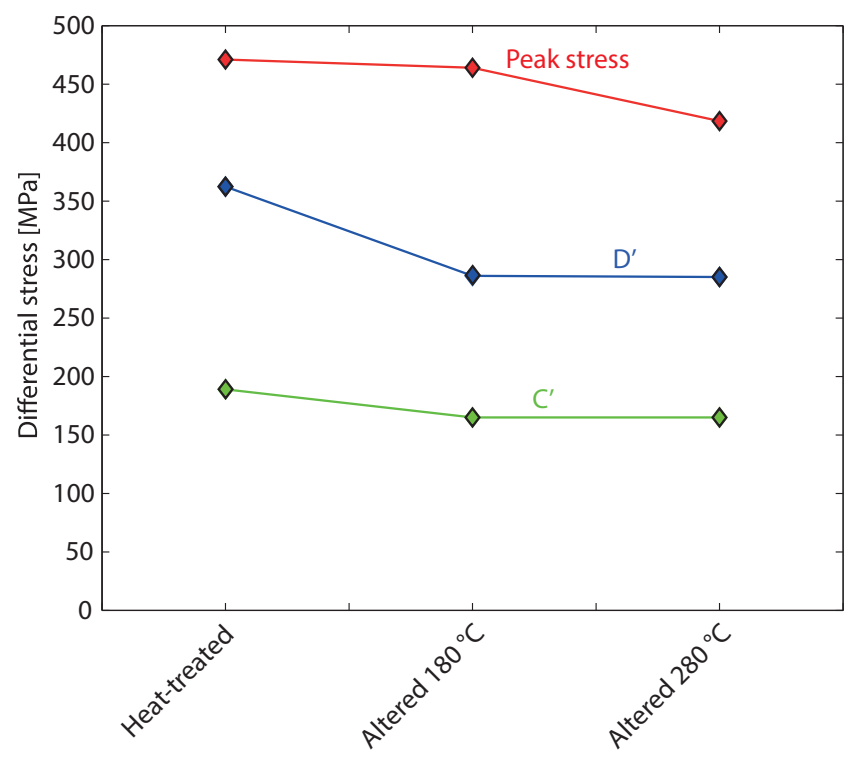

Figure 8. Differential stress at the peak stress (red diamonds), at the onset of dilatancy C' (green diamonds), and at dilatancy D' (blue diamonds) are shown for an heat-treated sample non-altered, and samples altered at 180 and $280^{\circ} \mathrm{C}$. All samples were triaxially deformed at a confining pressure of $15 \mathrm{MPa}$.

decrease of compaction with increasing alteration is in good agreement with crack filling because it is well known that cracks tend to close first under isostatic loading. Under triaxial stresses, it is known that the mechanical behaviour of brittle environments (in terms of elasticity and rupture) is much more susceptible to cracks than to equant pores, which may be in contradiction with the observations that crack porosity is filled by the products of alteration. However, damage models for brittle solids under compression show that the damage likely develops from pre-existing defects (e.g. cracks) and that the friction coefficient between the two flanks of these defects is of the utmost importance on the mechanical behaviour. Phyllosilicate minerals, and in particular smectite, are known to have low friction coefficients (e.g. Saffer et al. 2001; Moore \& Lockner 2007; Carpenter et al. 2011). Thus, our mechanical observations can be explained by the filling of pre-existing cracks by smectite. We thus conclude that alteration has led to the precipitation of smectite in cracks, which has induced an increase in elastic modulus of the material and a decrease of peak strength. Previous studies have also shown that phyllosilicates can have an influence on the mechanical behaviour (e.g. Bos \& Spiers 2002; Collettini et al. 2009)

\subsection{Modelling of crack propagation leading to failure in triaxial compression}

Triaxial constant-strain rate experiments on heat-treated and altered samples of andesite are modelled using well-known wing crack damage models initially developed by Nemat-Nasser \& Horii (1982), and later revisited by Ashby \& Hallam (1986), Ashby \& Sammis (1990), Bhat et al. (2011, 2012), Mallet et al. (2015), Perol \& Bhat (2016), Chanard et al. (2019) and Nicolas et al. (2017a), among others. Wings of length denoted $l$ can grow from each end of the pre-existing penny-shaped crack of radius $a$ inclined at an angle $\psi$ with respect to the maximum principal stress, parallel to the maximum principal stress (Fig. 10a). These wing cracks form an array of interacting cracks in an isotropic linear elastic surrounding medium subjected to compressive stresses (Fig. 10b). The faces of the initial crack, in contact, can slide with some friction characterized by a Coulomb friction coefficient $\mu$. We use Ashby \& Sammis (1990)'s approach to calculate the stress intensity factor $K_{\mathrm{I}}$ at the tip of the wings in a three-dimensional setting (Fig. 10), the wing crack growth and the resulting volumetric strain. Cracks grow when the stress intensity at their tips $K_{\mathrm{I}}$ exceeds the fracture toughness $K_{\mathrm{IC}}$ of the solid. Then, cracks propagate until $K_{\mathrm{I}}$ falls to $K_{\mathrm{IC}}$. Under compressive stresses as considered in this study, $K_{\mathrm{I}}$ decreases as $l$ increases until the cracks start to interact strongly: each increment of crack advance requires an increment of load and growth is stable. As wing cracks grow, the current damage increases. The crack can also open. Thus, three regimes need to be considered (Deshpande \& Evans 2008; Nicolas et al. 2017a): (i) Relative sliding on the flanks of the initial crack cannot take place because of friction, preventing cracks from growing. (ii) Relative sliding is possible and Ashby \& Sammis' approach is used. Expression of the stress intensity KI at the tip of interacting cracks forming an array is given by eq. (26) in Ashby \& Sammis (1990). (iii) Contact between the flanks of the initial crack is lost and the situation reduces to the classical problem for a cracked elastic solid (Bristow 1960; Budiansky \& O'Connell 1976; Tada et al. 2000). Precise description of the model can be found in Nicolas et al. (2017a), except that intracrystalline plasticity and new crack nucleation are not considered here (thus only Sections 2.1 and 2.2 should be considered in Nicolas et al.'s paper).

The elastic moduli of the uncracked porous medium used for our modelling are Young's modulus $E_{0}=50 \mathrm{GPa}$ and Poisson's ratio $v_{0}=0.15$. Any other set of elastic constants is calculated from these values. The critical stress intensity factor for andesite is taken equal to $K_{\mathrm{IC}}=2 \mathrm{MPa} \mathrm{m}^{1 / 2}$. This value corresponds to the value for dry andesite according to values measured by Nara et al. (2012) who found that fracture toughness for Kumamoto andesite is $K_{\mathrm{IC}}=$ $2.01-4 \times 10^{-3} h_{r} \mathrm{MPa} \mathrm{m}{ }^{1 / 2}$, where $h_{r}$ is relative humidity. This is in good agreement with measurements by Nara \& Kaneko (2005), Tutluoglu \& Keles (2011) and Siratovich et al. (2014) who found values ranging between 1 and $2 \mathrm{MPa} \mathrm{m}{ }^{1 / 2}$. It is also of the order of magnitude of the critical stress intensity factor measured for other volcanic rocks (e.g. Atkinson 1984).

Crack density (or initial damage) can be inferred from elastic wave velocity measurements (e.g. Sayers \& Kachanov 1995; Fortin et al. 2005; Regnet et al. 2018) or SEM images (e.g. Fredrich et al. 1989; Mallet et al. 2013). We use $D_{0}=0.1$, which is in good agreement with inverted crack densities. Initial damage (microcrack density) is kept constant in the modelling although results show that crack porosity decreases. Initial crack density is kept constant on purpose because the crack density ( $\sim c^{3}$, where $c$ is the crack length) is not directly related to the crack porosity $\left(\sim w c^{2}\right.$, where $w$ is the crack width and $c$ the crack length) but only to the crack length $c$. Thus, if smectite fills cracks (thus reducing their width, and thus reducing microcrack porosity) but does not modify the crack length and thus the crack density (damage).

Crack mean size can be inferred from SEM images (e.g. Mallet et al. 2013) or estimated by the grain size. In this study we use $a=2$ $\times 10^{-4} \mathrm{~m}$ for both altered and unaltered samples. Decreasing crack mean size would increase the peak stress and dilatancy at failure, as shown in Nicolas et al. (2017a).

Porosity can be measured using a triple weighting procedure. We use a porosity of 2 percent, which is a consistent value for low-porosity volcanic rocks. We do not take into account the slight porosity increase with alteration because porosity has very little influence on the predicted mechanical behaviour (Nicolas et al. 2017a). As shown in Nicolas et al. (2017a), a porosity increase of 

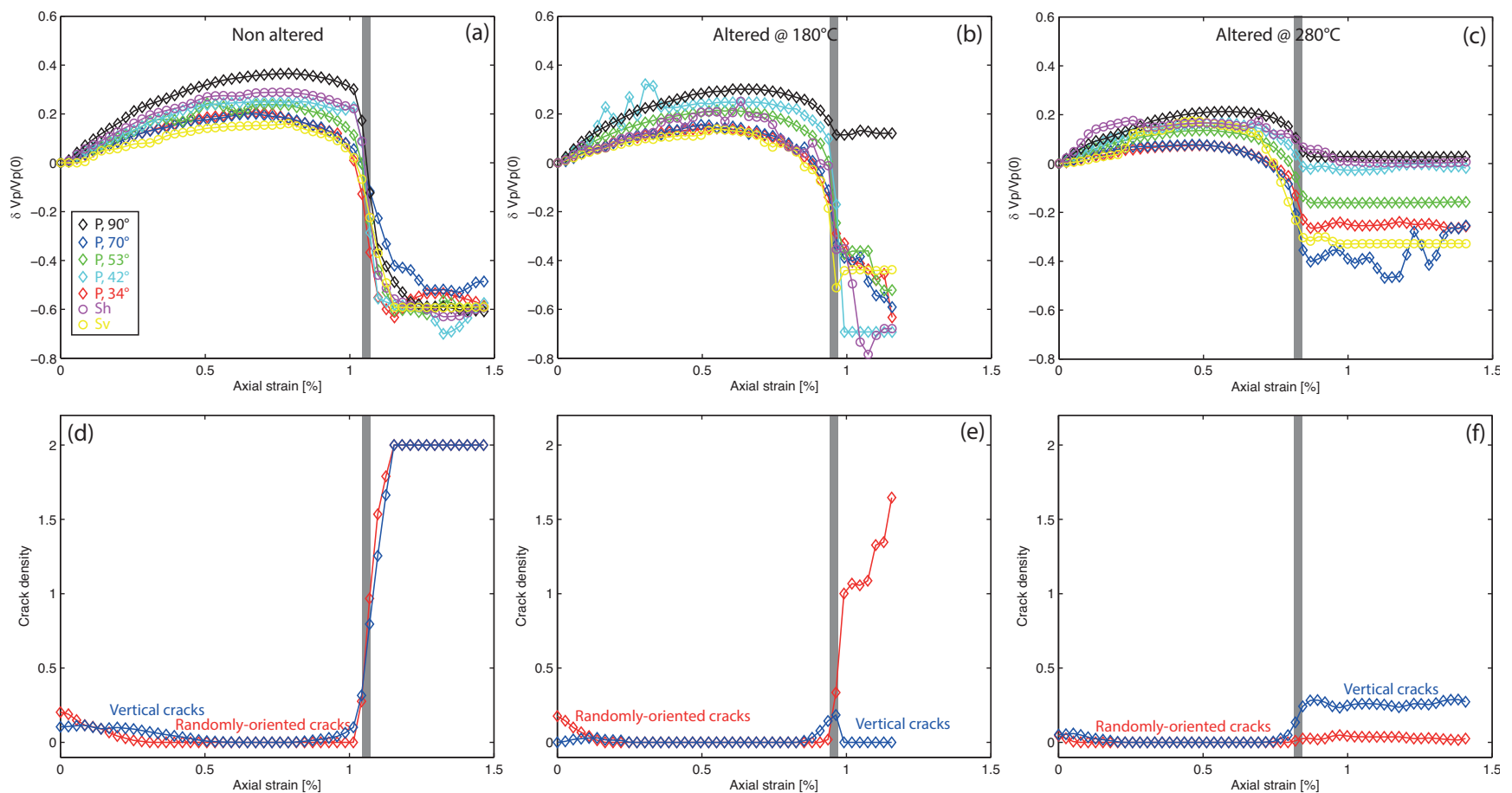

Figure 9. Evolution of $\delta V / V_{0}$ (where $V_{0}$ is the $P$ - or $S$-wave velocity at the beginning of triaxial loading, unitless) at different angles with respect to $\sigma_{1}$ is plotted as a function of axial strain for an heat-treated sample (a), and samples altered at $180{ }^{\circ} \mathrm{C}$ (b) and $280{ }^{\circ} \mathrm{C}$ (c). Evolution of axial and randomly oriented crack density (unitless) as a function of axial strain for an heat-treated sample (d), and samples altered at $180{ }^{\circ} \mathrm{C}$ (e) and $280{ }^{\circ} \mathrm{C}$ (f). The grey rectangles represent macroscopic failure.

(a)

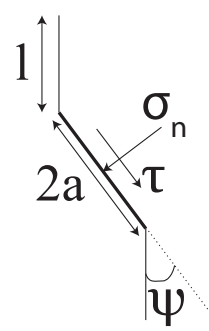

(b)

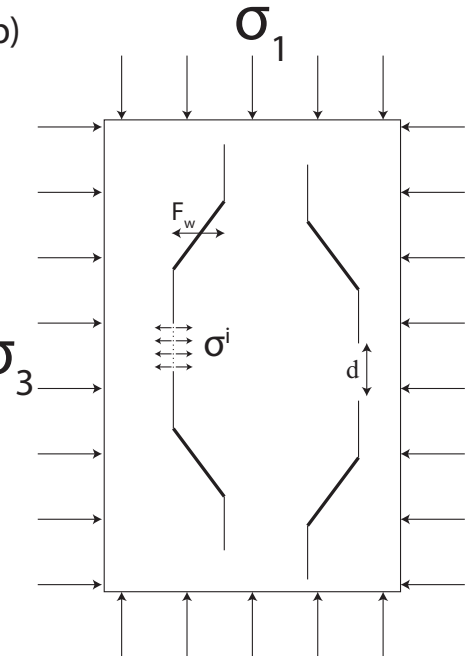

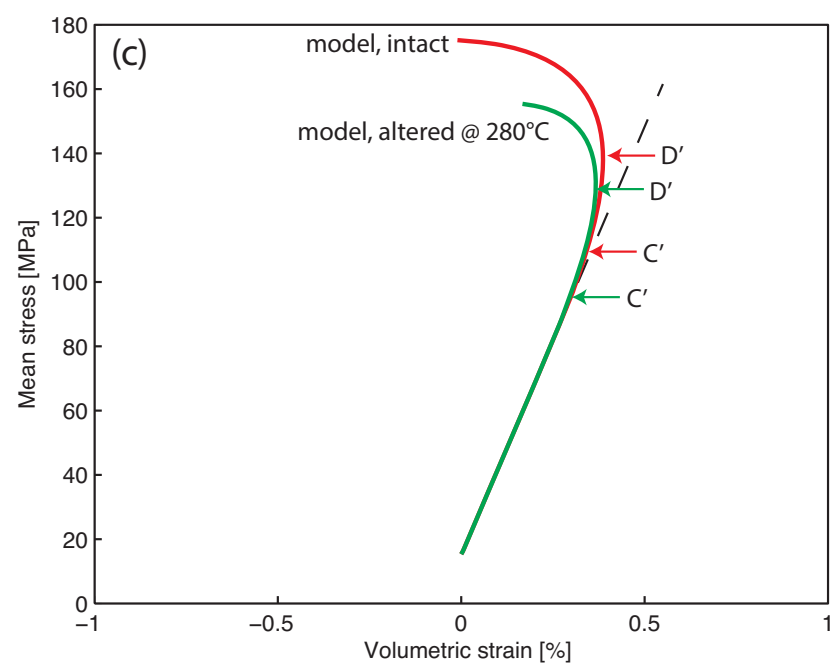

Figure 10. (a) A model of isolated wing-crack subjected to remote stress. Wings of length $l$ develop from an initial flaw of radius $a$ subjected to a normal stress $\sigma_{n}$ and a tangential stress $\tau$. Wings grow parallel to the maximum principal stress $\sigma_{1}$. (b) Geometry of the crack network used for the stress-intensity factor, $K_{\mathrm{I}}$, calculated at a crack tip. Cracks are subjected to a wedging force $F_{\mathrm{w}}$ that can be calculated from the remote load (maximum and minimal principal stresses $\sigma_{1}$ and $\sigma_{3}$, respectively) and crack interaction leads to an additional contribution $\sigma^{i}$ that increases as the intercrack distance $d$ decreases. (c) The model is run for a confining pressure of $15 \mathrm{MPa}$. Evolution of the mean stress as a function of volumetric strain for an heat-treated sample and a sample altered at $280{ }^{\circ} \mathrm{C}$. The red and green curves correspond to the heat-treated and altered at $280^{\circ} \mathrm{C}$ samples, respectively. Arrows show the onset of dilatancy $C^{\prime}$ and the point at which dilatancy overcomes compaction $\left(D^{\prime}\right)$ for each value of friction coefficient. Friction coefficient is the only parameter that was changed in the different simulations.

20 per cent induces a decrease of peak stress of less than 1 per cent. The friction coefficient on pre-existent penny-shaped cracks can be inferred from a linear failure envelope, assuming that friction is equal on a macroscopic fault and microcracks. Typical values for intact rocks are in the range [0.4-0.8], as shown by Byerlee (1978) for example. We use $\mu=0.5$ for the intact sample and $\mu=0.4$ for the altered sample due to the filling of cracks by clay minerals that have low friction coefficients (e.g. Kubo \& Katayama 2015; Tetsuka et al. 2018). This decrease of the friction coefficient is observed in many studies (e.g. Ohnaka 1975; Saffer et al. 2001; Tembe et al. 2010), 
although some measurements may remain unclear (e.g. Moore \& Lockner 2007).

Model predictions for unaltered and altered samples show that reducing the friction coefficient between the flanks of the crack (due to the presence of smectite) and keeping the damage ( $\sim$ crack density) constant leads to decreases of the onset of dilatancy $C$ ', the dilatancy point $D^{\prime}$ (represented by arrows) and the peak stress and increases the volumetric strain at the peak stress (Fig. 10c). Model predictions are in good agreement with the experimental results on failure properties and tend to confirm that the decrease of friction coefficient on pre-existing flaws due to clay minerals filling the cracks can explain the changes in the mechanical behaviour under triaxial loading. Note that the wing crack model cannot rule out the hypothesis of a decreasing peak strength with increasing alteration due to a decrease of the critical stress intensity factor $\left(K_{\mathrm{IC}}\right)$ with increasing alteration.

\subsection{Implications}

Our results have implications in several domains related to volcanic areas. Inflation and deflation of deep magma chambers induce the deformation of Earth's crust (e.g. Dvorak \& Dzurisin 1997; Walwer et al. 2016). Elastic properties of volcanic rocks are used in models used to invert geodetic data measurements (deformation of volcanoes) to derive constraints on the depth and pressure variations of volcanic chambers (e.g. Anderson 1937; Mogi 1958; McTigue 1987). Thus, volcanic rock mechanical properties and their variation with alteration are of the utmost importance as calculated depth and pressure variations of volcanic chambers are sensitive to the structure and chosen elastic parameters (e.g. Galland \& Scheibert 2013). Our results suggest elastic parameters are likely to vary locally, thus causing complications to calculate mean values for elastic parameters (e.g. Heap et al. 2020).

According to the most simple model (Mogi 1958), the volcano vertical surface uplift is proportional to the pressure increment in the magmatic chamber and inversely proportional to the elastic shear modulus (if the medium is considered as homogeneous). However, our results show that even though volcanoes may be made up of only one kind of rock, alteration due to hot fluid flows may induce changes of the mechanical properties of the rock. Thus, taking into account this elastic moduli dependence on alteration could be of interest to model surface uplifts due to a pressure increment in magmatic chambers and other surface deformation associated with volcanism (e.g. Galland \& Scheibert 2013; Le Mével et al. 2016). Our results suggest that special attention should be brought to the choice of representative elastic parameters in volcanic contexts since they can vary locally due to rock alteration.

Seismic velocities in volcanic areas are known to vary in space and time (e.g. Ratdomopurbo \& Poupinet 1995), for example due to the presence of pressurized fluids (e.g. Brenguier et al. 2014). Increase in elastic moduli has an impact on the elastic wave velocities observed during seismic campaigns. From our study, we suggest that an increased elastic wave velocity in the field can indicate an area of altered rocks, in the case of crystalline volcanic rocks, where porosity is dominated by fractures (dike intrusion, ...). Volcanic rocks, such as hyaloclastites and tuffs, are usually much more porous than andesite, so that the influence of alteration on mechanical properties might differ.

Failure models were developed to predict volcanic eruptions (e.g. Main 1999; De la Cruz-Reyna \& Reyes-Dávila 2001; Connor et al. 2003). Some of these models are based on the brittle characteristics of the materials forming volcanoes (e.g. Denlinger 1990). Fracture toughness is used in some of these models (e.g. Gudmundsson 2009). Thus, our measurements of the influence of alteration on the peak strength of andesite may have relevance for volcanic eruption models. Our results suggest that special attention should be brought to the choice of peak stress representative of the rock mass in volcanic contexts since failure parameters can vary locally due to rock alteration.

\section{CONCLUSION}

Most studies on the mechanical behaviour of volcanic rocks have focused on unaltered rocks samples and the specific influence of alteration on the mechanical behaviour of fractured geothermal reservoirs is still poorly understood. Yet, the presence of alteration minerals is susceptible to significantly modify the mechanical behaviour of rock, as compared to pure and unaltered rock, because alteration results in microstructural changes, which in turn modifies the physical (porosity, open crack density, velocity of propagation of elastic waves, permeability) and therefore mechanical properties of the rock.

Our experiments performed on samples artificially altered to different degrees have focused on the evolution of the mechanical behaviour under hydrostatic and differential stresses with alteration. Heat-treated cores drilled in a homogeneous block of natural andesite were artificially altered to different degrees. Artificial alteration products were characterized and quantified by means of quantitative analyses of XRD patterns and CEC measurements. Porosity and elastic wave velocities at ambient pressure and $50 \mathrm{MPa}$ were measured and both increase with the degree of alteration. The samples were then loaded isostatically and in a triaxial setting for samples deformed at a constant strain rate. Elastic moduli increase while peak strength decreases with alteration.

In wing crack models, a decrease of friction coefficient between the two flanks of pre-existing flaws can explain the mechanical observations. The decrease of friction coefficient can be explained by smectite precipitation in the pre-existing cracks, as phyllosilicate minerals, and in particular smectite, are known to have low friction coefficients. Crack filling with smectite is in agreement with SEM observations on thin sections (Fig. 5).

Our mechanical results have implications for several domains related to volcanic areas, on a fundamental and applied point of view. Alteration should be quantified during field work and then taken into account in mechanical modelling and inversion of geodetic data.

\section{ACKNOWLEDGEMENTS}

AN thanks Damian Walwer for its comments on volcano deformation. LL thanks the Icelandic Geosurvey (ISOR) for allowing CEC measurements in their facility. The authors thank Fleurice Parat (Geosciences Montpellier - UMR 5243) for performing XRF analysis. The authors thank the Editor and two anonymous reviewers for their constructive comments, which led to significant improvements of the manuscript.

This study was performed in the frame of GEOTREF project, aiming at improving our understanding of the behaviour of fractured geothermal reservoirs through a multidisciplinary platform for innovation and demonstration activities for the exploration and development of high geothermal energy in fractured reservoirs. Data presented in this paper are available on request. 


\section{REFERENCES}

Adelinet, M., Fortin, J., Guéguen, Y., Schubnel, A. \& Geoffroy, L., 2010. Frequency and fluid effects on elastic properties of basalt: experimental investigations, Geophys. Res. Lett., 37(2), doi:10.1029/2009GL041660.

Adelinet, M., Dorbath, C., Le Ravalec, M., Fortin, J. \& Guéguen, Y., 2011. Deriving microstructure and fluid state within the Icelandic crust from the inversion of tomography data, Geophys. Res. Lett., 38(3), doi:10.1029/2010GL046304.

Adelinet, M., Fortin, J., Schubnel, A. \& Guéguen, Y., 2013. Deformation modes in an Icelandic basalt: from brittle failure to localized deformation bands, J. Volc. Geotherm. Res., 255, 15-25.

Akamatsu, Y., Hatakeyama, K. \& Katayama, I., 2019. Contrasting dilatant behaviors of mafic and ultramafic rocks based on triaxial deformation experiments, J. Mineral. Petrol. Sci., 114(2), 79-86.

Anderson, E.M., 1937. Ix. The dynamics of the formation of cone-sheets, ring-dykes, and caldron-subsidences, Proc. R. Soc. Edinburgh, 56, 128157.

Ashby, M. \& Hallam, S., 1986. The failure of brittle solids containing small cracks under compressive stress states, Acta Metall., 34(3), 497-510.

Ashby, M. \& Sammis, C.G., 1990. The damage mechanics of brittle solids in compression, Pure appl. Geophys., 133, 489-521.

Atkinson, B.K., 1984. Subcritical crack growth in geological materials, $J$. geophys. Res., 89(B6), 4077-4114.

Ayling, M.R., Meredith, P.G. \& Murrell, S.A., 1995. Microcracking during triaxial deformation of porous rocks monitored by changes in rock physical properties, I. Elastic-wave propagation measurements on dry rocks, Tectonophysics, 245(3), 205-221.

Baud, P., Schubnel, A. \& Wong, T.-F., 2000. Dilatancy, compaction, and failure mode in Solnhofen limestone, J. geophys. Res., 105(B8), 19289 19303.

Beauchamps, G., Ledésert, B., Hébert, R., Navelot, V. \& Favier, A., 2019. The characterisation of an exhumed high-temperature paleo-geothermal system on Terre-de-Haut Island (the Les Saintes archipelago, Guadeloupe) in terms of clay minerals and petrophysics, Geother. Ener., 7(1), 6, doi:10.1186/s40517-019-0122-y.

Bhat, H., Sammis, C. \& Rosakis, A., 2011. The micromechanics of Westerley granite at large compressive loads, 168(12), 2181-2198.

Bhat, H.S., Rosakis, A.J. \& Sammis, C.G., 2012. A micromechanics based constitutive model for brittle failure at high strain rates, J. Appl. Mech., 79(3), 031016, doi:10.1115/1.4005897.

Bos, B. \& Spiers, C.J., 2002. Frictional-viscous flow of phyllosilicatebearing fault rock: microphysical model and implications for crustal strength profiles, J. geophys. Res., 107(B2), ECV 1-1-ECV 1-13.

Brantut, N., Schubnel, A. \& Guéguen, Y., 2011. Damage and rupture dynamics at the brittle-ductile transition: the case of gypsum, J. geophys. Res., 116(B1), doi:10.1029/2010JB007675.

Brenguier, F., Campillo, M., Takeda, T., Aoki, Y., Shapiro, N., Briand, X., Emoto, K. \& Miyake, H., 2014. Mapping pressurized volcanic fluids from induced crustal seismic velocity drops, Science, 345(6192), 80-82.

Bristow, J.R., 1960. Microcracks, and the static and dynamic elastic constants of annealed and heavily cold-worked metals, Br. J. Appl. Phys., 11(2), 81, doi:10.1088/0508-3443/11/2/309.

Browne, P., 1978. Hydrothermal alteration in active geothermal fields, Ann. Rev. Earth planet. Sci., 6(1), 229-248.

Budiansky, B. \& O'Connell, R.J., 1976. Elastic moduli of a cracked solid, Int. J. Solids Struct., 12(2), 81-97.

Byerlee, J., 1978. Friction of rocks, in Rock Friction and Earthquake Prediction, pp. 615-626, Springer.

Carpenter, B., Marone, C. \& Saffer, D., 2011. Weakness of the San Andreas Fault revealed by samples from the active fault zone, Nat. Geosci., 4(4), 251, doi:10.1038/ngeo1089.

Chanard, K., Nicolas, A., Hatano, T., Petrelis, F., Latour, S., Vinciguerra, S. \& Schubnel, A., 2019. Sensitivity of acoustic emission triggering to small pore pressure cycling perturbations during brittle creep, Geophys. Res. Lett., 46(13), 7414-7423.

Chester, F.M., et al., 2013. Structure and composition of the plate-boundary slip zone for the 2011 Tohoku-Oki earthquake, Science, 342(6163), 12081211.
Collettini, C., Niemeijer, A., Viti, C. \& Marone, C., 2009. Fault zone fabric and fault weakness, Nature, 462(7275), 907-910.

Connor, C.B., Sparks, R., Mason, R., Bonadonna, C. \& Young, S., 2003. Exploring links between physical and probabilistic models of volcanic eruptions: the Soufriere Hills Volcano, Montserrat, Geophys. Res. Lett., 30(13).

Darot, M., Guéguen, Y. \& Baratin, M., 1992. Permeability of thermally cracked granite, Geophys. Res. Lett., 19, 869-872.

De la Cruz-Reyna, S. \& Reyes-Dávila, G.A., 2001. A model to describe precursory material-failure phenomena: applications to short-term forecasting at Colima volcano, Mexico, Bull. Volcanol., 63(5), 297-308.

Denlinger, R., 1990. A model for dome eruptions at Mount St. Helens, Washington based on subcritical crack growth, in Lava Flows and Domes, pp. 70-87, Springer.

Deshpande, V. \& Evans, A.G., 2008. Inelastic deformation and energy dissipation in ceramics: a mechanism-based constitutive model, J. Mech. Phys. Solids, 56, 3077-3100.

Drits, V., Besson, G. \& Muller, F., 1995. An improved model for structural transformation of heat-treated aluminous dioctahedral 2: 1 layer silicates, Clays Clay Miner., 43(6), 718-731.

Dvorak, J.J. \& Dzurisin, D., 1997. Volcano geodesy: the search for magma reservoirs and the formation of eruptive vents, Rev. Geophys., 35(3), 343384

Fortin, J., Schubnel, A. \& Guéguen, Y., 2005. Elastic wave velocities and permeability evolution during compaction of Bleurswiller sandstone, Int. J. Rock Mech. Min. Sci., 42(7), 873-889.

Fortin, J., Stanchits, S., Dresen, G. \& Guéguen, Y., 2006. Acoustic emission and velocities associated with the formation of compaction bands in sandstone, J. geophys. Res., 111(B10), doi:10.1029/2005JB003854.

Fortin, J., Guéguen, Y. \& Schubnel, A., 2007. Effects of pore collapse and grain crushing on ultrasonic velocities and $\mathrm{Vp} / \mathrm{Vs}$, J. geophys. Res., 112(B8), doi:10.1029/2005JB004005.

Fortin, J., Stanchits, S., Dresen, G. \& Gueguen, Y., 2009. Acoustic emissions monitoring during inelastic deformation of porous sandstone: comparison of three modes of deformation, Pure appl. Geophys., 166(5-7), 823-841.

Fortin, J., Stanchits, S., Vinciguerra, S. \& Guéguen, Y., 2011. Influence of thermal and mechanical cracks on permeability and elastic wave velocities in a basalt from Mt. Etna volcano subjected to elevated pressure, Tectonophysics, 503(1), 60-74.

Fredrich, J.T. \& Wong, T.-F., 1986. Micromechanics of thermally induced cracking in three crustal rocks, J. geophys. Res., 91(B12), 12743-12764.

Fredrich, J.T., Evans, B. \& Wong, T.-F., 1989. Micromechanics of the brittle to plastic transition in Carrara marble, J. geophys. Res., 94(B4), 41294145.

Frolova, J., Ladygin, V., Rychagov, S. \& Zukhubaya, D., 2014. Effects of hydrothermal alterations on physical and mechanical properties of rocks in the Kuril-Kamchatka island arc, Eng. Geol., 183, 80-95.

Galland, O. \& Scheibert, J., 2013. Analytical model of surface uplift above axisymmetric flat-lying magma intrusions: implications for sill emplacement and geodesy, J. Volc. Geotherm. Res., 253, 114-130.

Geoffroy, L. \& Dorbath, C., 2008. Deep downward fluid percolation driven by localized crust dilatation in Iceland, Geophys. Res. Lett., 35(17), doi:10.1029/2008GL034514.

Glover, P., Baud, P., Darot, M., Meredith, P., Boon, S., LeRavalec, M., Zoussi, S. \& Reuschle, T., 1995. $\alpha / \beta$ phase transition in quartz monitored using acoustic emissions, Geophys. J. Int., 120(3), 775-782.

Grechka, V. \& Kachanov, M., 2006. Effective elasticity of fractured rocks: a snapshot of the work in progress, Geophysics, 71, W45-W58.

Greene-Kelly, R., 1953. Irreversible dehydration in montmorillonite, Clay Miner., 2, 52-56.

Grim, R.E. \& Rowland, R.A., 1944. Differential thermal analysis of clays and shales, a control and prospecting method, J. Am. Ceram. Soc., 27(3), $65-76$.

Gudmundsson, A., 2009. Toughness and failure of volcanic edifices, Tectonophysics, 471(1-2), 27-35.

Heap, M., Baud, P., Meredith, P., Vinciguerra, S., Bell, A. \& Main, I., 2011. Brittle creep in basalt and its application to time-dependent volcano deformation, Earth planet. Sci. Lett., 307(1-2), 71-82. 
Heap, M., Lavallée, Y., Petrakova, L., Baud, P., Reuschle, T., Varley, N. \& Dingwell, D.B., 2014. Microstructural controls on the physical and mechanical properties of edifice-forming andesites at Volcán de Colima, Mexico, J. geophys. Res., 119(4), 2925-2963.

Heap, M., Farquharson, J., Baud, P., Lavallée, Y. \& Reuschlé, T., 2015a. Fracture and compaction of andesite in a volcanic edifice, Bull. Volcanol., 77(6), 55, doi:10.1007/s00445-015-0938-7.

Heap, M.J., Vinciguerra, S. \& Meredith, P., 2009. The evolution of elastic moduli with increasing crack damage during cyclic stressing of a basalt from Mt. Etna volcano, Tectonophysics, 471(1-2), 153-160.

Heap, M.J., et al., 2015b. Mechanical behaviour and failure modes in the Whakaari (White Island volcano) hydrothermal system, New Zealand, $J$. Volc. Geotherm. Res., 295, 26-42.

Heap, M.J., et al., 2017. A multidisciplinary approach to quantify the permeability of the Whakaari/White Island volcanic hydrothermal system (Taupo Volcanic Zone, New Zealand), J. Volc. Geotherm. Res., 332, 88108.

Heap, M.J., Villeneuve, M., Albino, F., Farquharson, J.I., Brothelande, E., Amelung, F., Got, J.-L. \& Baud, P., 2020. Towards more realistic values of elastic moduli for volcano modelling, J. Volc. Geotherm. Res., 390, doi:10.1016/j.jvolgeores.2019.106684.

Hyndman, R.D., Yamano, M. \& Oleskevich, D.A., 1997. The seismogenic zone of subduction thrust faults, Island Arc, 6(3), 244-260.

Jaud, P. \& Lamethe, D., 1985. The bouillante geothermal power-plant, guadeloupe, Geothermics, 14(2-3), 197-205.

Katayama, I., Nicolas, A. \& Schubnel, A., 2018. Fluid induced fracturing of initially damaged granite triggered by pore pressure buildup, Geophys. Res. Lett., 45(15), 7488-7495.

Keshavarz, M., Pellet, F. \& Loret, B., 2010. Damage and changes in mechanical properties of a gabbro thermally loaded up to 1,000 C, Pure appl. Geophys., 167(12), 1511-1523.

Kluge, C., Blöcher, G., Milsch, H., Hofmann, H., Nicolas, A., Li, Z. \& Fortin, J., 2017. Sustainability of fractured rock permeability under varying pressure, in Poromechanics VI, pp. 1192-1199.

Komorowski, J., Boudon, G., Semet, M., Beauducel, F., Anténor-Habazac, V., Bazin, S., Hammouya, G. \& Cheminée, J., 2005, Volcanic Hazard Atlas of the Lesser Antilles, University of the West Indies, pp. 63-100.

Kubo, T. \& Katayama, I., 2015. Effect of temperature on the frictional behavior of smectite and illite, J. Mineral. Petrol. Sci., 110(6), 293-299.

Le Bas, M., Le Maitre, R., Streckeisen, A. \& Zanettin, B., 1986. A chemical classification of volcanic rocks based on the total alkali-silica diagram, $J$. Petrol., 27, 745-750.

Le Mével, H., Gregg, P.M. \& Feigl, K.L., 2016. Magma injection into a long-lived reservoir to explain geodetically measured uplift: application to the 2007-2014 unrest episode at Laguna Del Maule volcanic field, chile, J. geophys. Res., 121(8), 6092-6108.

Lévy, L., Gibert, B., Sigmundsson, F., Flóvenz, O.G., Hersir, G.P., Briole, P. \& Pezard, P.A., 2018. The role of smectites in the electrical conductivity of active hydrothermal systems: electrical properties of core samples from Krafla volcano, Iceland, Geophys. J. Int., 215(3), 1558-1582.

Lévy, L., Gibert, B., Sigmundsson, F., Deldicque, D., Parat, F. \& Hersir, G., 2019a. Tracking magmatic hydrogen sulfur circulations using electrical impedance: complex electrical properties of core samples at the krafla volcano, iceland, J. geophys. Res., 124(3), 2492-2509.

Lévy, L., et al., 2019b. Electrical resistivity tomography and time-domain induced polarization field investigations of geothermal areas at Krafla, Iceland: comparison to borehole and laboratory frequency-domain electrical observations, Geophys. J. Int., 218(3), 1469-1489.

Lévy, L., Weller, A. \& Gibert, B., 2019c. Influence of smectite and salinity on the imaginary and surface conductivity of volcanic rocks, Near Surf. Geophys., 17(6), 653-673.

Lévy, L., Fridriksson, T., Findling, N., Lanson, B., Fraisse, B., Marino, N. \& Gibert, B., 2020. Smectite quantification in hydrothermally altered volcanic rocks, Geothermics, 85, 101748.

Li, Z., Fortin, J., Nicolas, A., Deldicque, D. \& Guéguen, Y., 2019. Physical and mechanical properties of thermally cracked andesite under pressure, Rock Mech. Rock Eng., 1-21.
Mackenzie, R., 1957. The montmorillonite differential thermal curve. I.General variability in the dehydroxylation region, Bulletin du Groupe francais des argiles, 9(4), 7-15.

Main, I.G., 1999. Applicability of time-to-failure analysis to accelerated strain before earthquakes and volcanic eruptions, Geophys. J. Int., 139(3), F1-F6.

Malek, Z., Balek, V., Garfinkel-Shweky, D. \& Yariv, S., 1997. The study of the dehydration and dehydroxylation of smectites by emanation thermal analysis, J. Therm. Anal., 48(1), 83-92.

Mallet, C., Fortin, J., Guéguen, Y. \& Bouyer, F., 2013. Effective elastic properties of cracked solids: an experimental investigation, Int. J. Fract., 182(2), 275-282.

Mallet, C., Fortin, J., Guéguen, Y. \& Bouyer, F., 2015. Brittle creep and subcritical crack propagation in glass submitted to triaxial conditions, $J$. geophys. Res., 120(2), 879-893.

Massonnet, D. \& Sigmundsson, F., 2000. Remote sensing of volcano deformation by radar interferometry from various satellites, Rem. Sens. Active Volcanol., 207-221.

Mavko, G., Mukerji, T. \& Godfrey, N., 1995. Predicting stress-induced velocity anisotropy in rocks, Geophysics, 60(4), 1081-1087.

McTigue, D., 1987. Elastic stress and deformation near a finite spherical magma body: resolution of the point source paradox, J. geophys. Res., 92(B12), 12 931-12940.

Meier, L. \& Kahr, G., 1999. Determination of the cation exchange capacity (CEC) of clay minerals using the complexes of copper(II) ion with triethylenetetramine and tetraethylenepentamine, Clays Clay Miner., 47(3), 386-388.

Meller, C. \& Kohl, T., 2014. The significance of hydrothermal alteration zones for the mechanical behavior of a geothermal reservoir, Geotherm. Ener, 2(1), 12, doi:10.1186/s40517-014-0012-2.

Meunier, A., 2005. Clays, Springer Science \& Business Media.

Mogi, K., 1958. Relations between the eruptions of various volcanoes and the deformations of the ground surfaces around them., Earthq. Res. Inst., 36, 99-134.

Moore, D.E. \& Lockner, D.A., 2007. Friction of the smectite clay montmorillonite, in The Seismogenic Zone of Subduction Thrust Faults, pp. 317-345, eds Dixon, T. \& Moore, C., Columbia Univ. Press.

Mordensky, S., Villeneuve, M., Kennedy, B., Heap, M., Gravley, D., Farquharson, J. \& Reuschlé, T., 2018. Physical and mechanical property relationships of a shallow intrusion and volcanic host rock, pinnacle ridge, Mt. Ruapehu, New Zealand, J. Volc. Geotherm. Res., 359, 1-20.

Mordensky, S., Heap, M., Kennedy, B., Gilg, H., Villeneuve, M., Farquharson, J. \& Gravley, D., 2019. Influence of alteration on the mechanical behaviour and failure mode of andesite: implications for shallow seismicity and volcano monitoring, Bull Volcanol, 81, doi:10.1007/s00445-0191306-9.

Nara, Y. \& Kaneko, K., 2005. Study of subcritical crack growth in andesite using the double torsion test, Int. J. Rock Mech. Min. Sci., 42(4), 521-530.

Nara, Y., Morimoto, K., Hiroyoshi, N., Yoneda, T., Kaneko, K. \& Benson, P.M., 2012. Influence of relative humidity on fracture toughness of rock: implications for subcritical crack growth, Int. J. Solids Struct., 49(18), 2471-2481.

Nara, Y., Yamanaka, H., Oe, Y. \& Kaneko, K., 2013. Influence of temperature and water on subcritical crack growth parameters and long-term strength for igneous rocks, Geophys. J. Int., 193(1), 47-60.

Navelot, V., et al., 2018. Petrophysical properties of volcanic rocks and impacts of hydrothermal alteration in the Guadeloupe Archipelago (West Indies), J. Volc. Geotherm. Res., 360, 1-21.

Nemat-Nasser, S. \& Horii, H., 1982. Compression-induced nonplanar crack extension with application to splitting, exfoliation, and rockburst, $J$. geophys. Res., 87(B8), 6805-6821.

Nicolas, A., Girault, F., Schubnel, A., Pili, É., Passelègue, F., Fortin, J. \& Deldicque, D., 2014. Radon emanation from brittle fracturing in granites under upper crustal conditions, Geophys. Res. Lett., 41(15), 5436-5443.

Nicolas, A., Fortin, J., Regnet, J., Dimanov, A. \& Guéguen, Y., 2016. Brittle and semi-brittle behaviours of a carbonate rock: influence of water and temperature, Geophys. J. Int., 206(1), 438-456. 
Nicolas, A., Fortin, J. \& Guéguen, Y., 2017a. Micromechanical constitutive model for low-temperature constant strain rate deformation of limestones in the brittle and semi-brittle regime, Geophys. J. Int., 211(1), 300-321.

Nicolas, A., Fortin, J., Regnet, J., Verberne, B., Plümper, O., Dimanov, A., Spiers, C. \& Guéguen, Y., 2017b. Brittle and semi-brittle creep of gavel limestone deformed at room temperature, J. geophys. Res., doi:10.1093/gji/ggw154.

Nicolas, A., et al., 2020. Pore pressure pulse migration in microcracked andesite recorded with fibre optic sensors, Geomech. Ener. Environ., 24,

Ohnaka, M., 1975. Frictional characteristics of typical rocks, J. Phys. Earth, 23(1), 87-112.

Ougier-Simonin, A., Fortin, J., Guéguen, Y., Schubnel, A. \& Bouyer, F., 2011. Cracks in glass under triaxial conditions, Int. J. Eng. Sci., 49(1), $105-121$.

Pagli, C., Sigmundsson, F., Arnadóttir, T., Einarsson, P. \& Sturkell, E., 2006. Deflation of the Askja volcanic system: constraints on the deformation source from combined inversion of satellite radar interferograms and GPS measurements, J. Volc. Geotherm. Res., 152(1-2), 97-108.

Passelègue, F.X., Fabbri, O., Dubois, M. \& Ventalon, S., 2014. Fluid overpressure along an Oligocene out-of-sequence thrust in the Shimanto Belt, SW Japan, J. Asian Earth Sci., 86, 12-24.

Pedersen, R. \& Sigmundsson, F., 2004. InSAR based sill model links spatially offset areas of deformation and seismicity for the 1994 unrest episode at Eyjafjallajökull volcano, Iceland, Geophys. Res. Lett., 31(14), doi:10.1029/2004GL020368.

Perol, T. \& Bhat, H.S., 2016. Micromechanics-based permeability evolution in brittle materials at high strain rates, Pure appl. Geophys., 173(8), 28572868.

Pola, A., Crosta, G., Fusi, N., Barberini, V. \& Norini, G., 2012. Influence of alteration on physical properties of volcanic rocks, Tectonophysics, $\mathbf{5 6 6}$, 67-86.

Ratdomopurbo, A. \& Poupinet, G., 1995. Monitoring a temporal change of seismic velocity in a volcano: application to the 1992 eruption of Mt. Merapi (Indonesia), Geophys. Res. Lett., 22(7), 775-778.

Regnet, J.-B., Fortin, J., Nicolas, A., Pellerin, M. \& Guéguen, Y., 2018. Elastic properties of continental carbonates: from controlling factors to an applicable model for acoustic-velocity predictions, Geophysics, 84(1), MR45-MR59.

Reyes, A.G., 1990. Petrology of philippine geothermal systems and the application of alteration mineralogy to their assessment, J. Volc. Geotherm. Res., 43(1-4), 279-309.

Rimsaite, J., 1975. Natural alteration of mica and reactions between released ions in mineral deposits, Clays Clay Miner., 23(3), 247-55.

Russell, J. \& Farmer, V., 1964. Infra-red spectroscopic study of the dehydration of montmorillonite and saponite, Clay Miner. Bull., 5(32), 443-464.

Saffer, D.M., Frye, K.M., Marone, C. \& Mair, K., 2001. Laboratory results indicating complex and potentially unstable frictional behavior of smectite clay, Geophys. Res. Lett., 28(12), 2297-2300.

Samper, A., Quidelleur, X., Lahitte, P. \& Mollex, D., 2007. Timing of effusive volcanism and collapse events within an oceanic arc island: Basseterre, guadeloupe archipelago (lesser antilles arc), Earth planet. Sci. Lett., 258(1-2), 175-191.

Sayers, C.M. \& Kachanov, M., 1995. Microcrack-induced elastic wave anisotropy of brittle rocks, J. geophys. Res., 100(B3), 4149-4156.

Siratovich, P., Heap, M., Villeneuve, M., Cole, J., Kennedy, B., Davidson, J. \& Reuschlé, T., 2016. Mechanical behaviour of the Rotokawa Andesites (New Zealand): insight into permeability evolution and stress-induced behaviour in an actively utilised geothermal reservoir, Geothermics, 64, 163-179.

Siratovich, P.A., Heap, M.J., Villenueve, M.C., Cole, J.W. \& Reuschlé, T., 2014. Physical property relationships of the Rotokawa Andesite, a significant geothermal reservoir rock in the Taupo Volcanic Zone, New Zealand, Geotherm. Ener, 2(1), 10, doi:10.1186/s40517-014-0010-4.
Skjerlie, K.P. \& Johnston, A.D., 1992. Vapor-absent melting at 10 kbar of a biotite-and amphibole-bearing tonalitic gneiss: implications for the generation of a-type granites, Geology, 20(3), 263-266.

Stanchits, S., Vinciguerra, S. \& Dresen, G., 2006. Ultrasonic velocities, acoustic emission characteristics and crack damage of basalt and granite, Pure appl. Geophys., 163(5-6), 975-994.

Tada, H., Paris, P.C. \& Irwin, G.R., 2000. The Stress Analysis of Cracks Handbook. The American Society of Mechanical Engineers.

Taut, T., Kleeberg, R. \& Bergmann, J., 1998. Seifert software: the new Seifert Rietveld Program BGMN and its application to quantitative phase analysis, Mater. Struct., 5(1), 57-66.

Tembe, S., Lockner, D.A. \& Wong, T.-F., 2010. Effect of clay content and mineralogy on frictional sliding behavior of simulated gouges: binary and ternary mixtures of quartz, illite, and montmorillonite, J. geophys. Res., 115(B3), doi:10.1029/2009JB006383.

Tetsuka, H., Katayama, I., Sakuma, H. \& Tamura, K., 2018. Effects of humidity and interlayer cations on the frictional strength of montmorillonite, Earth, Planets Space, 70(1), 56.

Traineau, H., Sanjuan, B., Beaufort, D., Brach, M., Castaing, C., Correia, H., Genter, A. \& Herbrich, B., 1997. The bouillante geothermal field (FWI) revisited: new data on the fractured geothermal reservoir in light of a future stimulation experiment in a low productive well, in Proceedings of the 22nd Workshop on Geothermal Reservoir Engineering, Stanford University, SGP-TR-155.

Tutluoglu, L. \& Keles, C., 2011. Mode I fracture toughness determination with straight notched disk bending method, Int. J. Rock Mech. Min. Sci., 48(8), 1248-1261.

Vajdova, V., Baud, P. \& Wong, T.-F., 2004. Compaction, dilatancy, and failure in porous carbonate rocks, J. geophys. Res., 109(B5), doi:10.1029/2003JB002508.

Vinciguerra, S., Trovato, C., Meredith, P. \& Benson, P., 2005. Relating seismic velocities, thermal cracking and permeability in Mt. Etna and Iceland Basalts, Int. J. Rock Mech. Min. Sci., 42(7-8), 900-910.

Walsh, J.B., 1965. The effect of cracks on the compressibility of rock, $J$. geophys. Res., 70(2), 381-389.

Walwer, D., Calais, E. \& Ghil, M., 2016. Data-adaptive detection of transient deformation in geodetic networks, J. geophys. Res., 121(3), 2129-2152.

Wang, X.-Q., Schubnel, A., Fortin, J., David, E., Guéguen, Y. \& Ge, H.-K., 2012. High Vp/Vs ratio: saturated cracks or anisotropy effects?, Geophys. Res. Lett., 39(11), doi:10.1029/2012GL051742.

Wang, X.-Q., Schubnel, A., Fortin, J., Guéguen, Y. \& Ge, H.-K., 2013. Physical properties and brittle strength of thermally cracked granite under confinement, J. geophys. Res., 118(12), 6099-6112.

Wong, T.-F., David, C. \& Zhu, W., 1997. The transition from brittle faulting to cataclastic flow in porous sandstones: mechanical deformation, $J$. geophys. Res., 102(B2), 3009-3025.

Wyering, L., Villeneuve, M., Wallis, I., Siratovich, P., Kennedy, B., Gravley, D. \& Cant, J., 2014. Mechanical and physical properties of hydrothermally altered rocks, Taupo Volcanic Zone, New Zealand, J. Volc. Geotherm. Res., 288, 76-93.

Yamaguchi, A., et al., 2011. Progressive illitization in fault gouge caused by seismic slip propagation along a megasplay fault in the Nankai Trough, Geology, 39(11), 995-998.

Zhan, W. \& Guggenheim, S., 1995. The dehydroxylation of chlorite and the formation of topotactic product phases, Clays Clay Miner., 43(5), $622-629$.

Zhu, W., Baud, P. \& Wong, T.-F., 2010. Micromechanics of cataclastic pore collapse in limestone, J. geophys. Res., 115(B4), doi:10.1029/2009JB006610.

Zimbelman, D., Rye, R.O. \& Breit, G., 2005. Origin of secondary sulfate minerals on active andesitic stratovolcanoes, Chem. Geol., 215(1-4), 3760 . 